\title{
Canine Primary Intracranial Cancer: A Clinicopathologic and Comparative Review of Glioma, Meningioma, and Choroid Plexus Tumors
}

\author{
Andrew D. Miller ${ }^{1 *}$, C. Ryan Miller ${ }^{2}$ and John H. Rossmeis/ ${ }^{3}$ \\ 1 Section of Anatomic Pathology, Department of Biomedical Sciences, Cornell University College of Veterinary Medicine, \\ Ithaca, NY, United States, ${ }^{2}$ Division of Neuropathology, Department of Pathology, O'Neal Comprehensive Cancer Center and \\ Comprehensive Neuroscience Center, University of Alabama School of Medicine, Birmingham, AL, United States, ${ }^{3}$ Section of \\ Neurology and Neurosurgery, Veterinary and Comparative Neuro-Oncology Laboratory, Department of Clinical Sciences, \\ Virginia-Maryland College of Veterinary Medicine, Blacksburg, VA, United States
}

\section{OPEN ACCESS}

Edited by:

Rodney L. Page,

Colorado State University,

United States

Reviewed by:

Justin Vareecal Joseph,

Aarhus University, Denmark

M. Renee Chambers,

University of Alabama at Birmingham,

United States

*Correspondence:

Andrew D. Miller

adm10@cornell.edu

Specialty section

This article was submitted to

Cancer Molecular Targets and

Therapeutics,

a section of the journal

Frontiers in Oncology

Received: 09 August 2019

Accepted: 16 October 2019

Published: 08 November 2019

Citation:

Miller AD, Miller CR and Rossmeis/ JH (2019) Canine Primary Intracranial Cancer: A Clinicopathologic and Comparative Review of Glioma, Meningioma, and Choroid Plexus Tumors. Front. Oncol. 9:1151. doi: 10.3389/fonc.2019.01151
In the dog, primary intracranial neoplasia represents $\sim 2-5 \%$ of all cancers and is especially common in certain breeds including English and French bulldogs and Boxers. The most common types of primary intracranial cancer in the dog are meningioma, glioma, and choroid plexus tumors, generally occurring in middle aged to older dogs. Much work has recently been done to understand the characteristic imaging and clinicopathologic features of these tumors. The gross and histologic landscape of these tumors in the dog compare favorably to their human counterparts with many similarities noted in histologic patterns, subtype, and grades. Data informing the underlying molecular abnormalities in the canine tumors have only begun to be unraveled, but reveal similar pathways are mutated between canine and human primary intracranial neoplasia. This review will provide an overview of the clinicopathologic features of the three most common forms of primary intracranial cancer in the dog, delve into the comparative aspects between the dog and human neoplasms, and provide an introduction to current standard of care while also highlighting novel, experimental treatments that may help bridge the gap between canine and human cancer therapies.

Keywords: canine, glioma, meningioma, choroid plexus tumor, pathology, immunohistochemistry

\section{INTRODUCTION}

Dogs are the only mammalian species besides humans in which spontaneous brain tumors arise frequently (1-4). The estimated incidence of canine nervous system tumors is reported as 14.5 cases per 100,000 (5). Other studies indicate that intracranial neoplasms are observed in $2-4.5 \%$ of dogs that are subjected to post-mortem examinations $(2,4,5)$.

In dogs, $\sim 90 \%$ of primary brain tumors (PBT) encountered in clinical practice are represented by meningiomas $(\sim 50 \%)$, gliomas $(\sim 35 \%)$, and choroid plexus tumors (CPT; $\sim 7 \%)$, although the distribution of specific PBT in individual studies varies considerably (1-5). Other PBT, including ependymoma, germinoma, and embryonal tumors are all extremely rare, poorly defined outside of scattered case reports and series, and will not be considered in this review. Secondary brain tumors (SBT) comprise approximately one-half of all canine intracranial tumors, with hemangiosarcoma (29-35\%), lymphoma (12-20\%), and metastatic carcinomas (11-20\%) accounting for $77-86 \%$ of all SBT $(4,6)$. 
Brain tumors in dogs occur at any age and in any breed, and there are no reported sex predispositions. However, most PBT and SBT occur in middle-aged to older dogs, with the majority of cases described being $>5$ years of age $(3,4,7,8)$. Median ages at diagnosis for dogs with gliomas, meningiomas, and CPT are 8 years, 10.5 years, and 5.5 years, respectively $(3,4,7,8)$. There is a propensity for intracranial tumors identified in juvenile animals to be neuroepithelial tumors of glial, neuronal, or embryonal origin $(4,9)$. One study identified a statistically significant linear relationship between age and body weight and the occurrence of $\mathrm{PBT}$, and large breed dogs were at significantly increased risk for developing meningiomas and CPT (4). Golden retrievers, boxers, miniature schnauzers, and rat terriers have been identified as breeds in which intracranial meningiomas are overrepresented $(3,4)$.

Although CPT were also overrepresented in Golden Retrievers in one study (8), this breed predisposition was not substantiated in a subsequent investigation (4). Gliomas (astrocytomas, oligodendrogliomas, and undefined gliomas) are highly overrepresented in several brachycephalic breeds including boxers, Boston terrier, bullmastiffs, and English and French bulldogs (2-4). A locus on canine chromosome (CFA) 26 has been strongly associated with glioma risk across multiple dog breeds, with regional mapping revealing single nucleotide variants in three neighboring genes DENR, CAMKK2, and $P 2 R X 7$ that are highly associated with glioma susceptibility (10). The CAMKK2 and P2RX7 genes are relevant to the development or progression of human cancers (10). Further characterization of these genetic associations may provide insight into the drivers of gliomas in dogs and humans, identify new therapeutic targets, or decrease the incidence of gliomas in dogs through selective breeding strategies.

\section{PATHOPHYSIOLOGY AND CLINICAL SIGNS}

PBT are intracranial mass lesions that cause clinical signs of brain dysfunction by directly invading or compressing brain tissue and secondarily by causing peritumoral edema, neuroinflammation, obstructive hydrocephalus, and intracranial hemorrhage (11). Compensatory autoregulatory mechanisms, such as decreased cerebrospinal fluid (CSF) production and shifting of CSF into the spinal subarachnoid space, are effective at maintaining the intracranial pressure within physiologic ranges in the early phases of tumor growth. For slow-growing tumor types, such as meningiomas, intracranial pressure-volume homeostatic regulatory mechanisms can often remain intact despite large tumor volumes associated with significant mass effect. However, with progressive increases in tumor volume, autoregulatory mechanisms are eventually overwhelmed and intracranial hypertension ( $\mathrm{ICH}$ ) develops. $\mathrm{ICH}$ and the resulting cerebral hypoperfusion is the common pathophysiologic denominator underlying many of the mechanisms of tumor-associated brain injury. Acute clinical deterioration observed in animals with brain tumors and $\mathrm{ICH}$ is often the result of vasogenic edema, obstructive hydrocephalus, brain ischemia or hemorrhage, brain herniation, or combinations of these mechanisms (11).
A brain tumor should be considered a differential diagnosis in any middle-aged or older dog with a clinical history consistent with brain dysfunction, especially when clinical signs are progressive. Seizures are the most common clinical manifestation of intracranial neoplasia, and are observed in $\sim 50 \%$ of dogs with prosencephalic tumors $(3,12-17)$. Structural causes of epilepsy, such as brain tumors, should also be suspected in dogs that experience a new onset of seizure activity after 5 years of age, particularly in predisposed breeds (14). Risk factors for tumor-associated structural epilepsy identified on MRI scans in dogs include the presence of tumor involving the frontal lobe, falcine or subtentorial brain herniations, and marked contrast enhancement of the tumor (16). The pathophysiology of tumorrelated epilepsy is currently poorly understood, but both the tumoral and peritumoral microenvironments may contribute to epileptogenic phenotypes owing to disordered neuronal connectivity and regulation, impaired glial cell function, and the presence of altered vascular supply and permeability (1820). Central vestibular dysfunction is the most common clinical sign associated with brain tumors originating in the caudal brainstem $(14,21)$. Dogs with brain tumors may also present with non-specific clinical signs, such as lethargy, inappetence, and weight loss (22). Tumors in the fronto-olfactory region are often associated with only historical evidence of brain disease such as seizures or behavioral changes and a normal interictal neurological examination.

Most PBT in dogs occur as solitary mass lesions, and tumors involving forebrain structures are more common than those in the brainstem $(3,4,21)$. In many cases with solitary masses, the neurological deficits observed reflect the focal neuroanatomic area of the brain containing the tumor. However, dogs with PBT or SBT may also present with neurological deficits indicative of multifocal intracranial disease.

Multifocal clinical signs may result from several phenomena. The tumor or its secondary effects (vasogenic edema, brain herniation, or hemorrhage) may involve more than one region of the brain, which has been reported in up to $50 \%$ of dogs with solitary PBT (3). The phenotypes of some PBT, such as butterfly glioblastomas, diffuse glioma, or leptomeningeal oligodendrogliomatosis, are characterized by invasion of both cerebral hemispheres or diffuse brain or meningeal involvement (23-26). Multiple discrete tumor foci may also be present, which occurs occasionally in canine meningiomas and histiocytic sarcomas $(1,27)$. Rare reports describing synchronous PBT of different histologies, and concurrent PBT and SBT also exist $(28,29)$. PBT, and particularly choroid plexus carcinomas, may metastasize within the CNS by a unique mechanism termed drop metastases $(8,11,30)$. This involves exfoliation of cancer cells into and circulation within the CSF, with implantation of tumor foci distant from the site of the primary tumor in the ventricular system or subarachnoid space.

\section{DIAGNOSIS OF INTRACRANIAL TUMORS}

As brain tumors typically affect middle-aged to older dogs that may have significant concurrent disease, performance of a complete blood count, chemistry profile, and urinalysis is generally indicated in dogs with suspected brain tumors to 
evaluate the animal's systemic health status (3). These diagnostics also allow for rational formulation of an anesthetic protocol, as anesthesia is required for the performance of ancillary diagnostics that provide the highest diagnostic yield in dogs with structural brain disease, such as brain biopsy, magnetic resonance [MRI] imaging, and CSF analysis. Other diagnostics indicated prior to anesthesia are dictated by the individual dog's history and physical examination findings.

Radiographs of the thorax and abdominal ultrasound (AUS) should be considered in an attempt to identify concurrent unrelated neoplasia or other significant comorbidities. Studies in dogs with intracranial tumors report finding contemporaneous and unrelated neoplasms in $3-23 \%$ of dogs with PBT, most of which involve either the thoracic or abdominal cavity $(3,31)$. Additional studies investigating the clinical utility of screening thoracic radiography and AUS in dogs with intracranial tumors have indicated that abnormalities are frequently identified on these imaging examinations, the results of these procedures rarely negatively affect the decision to perform neurodiagnostic procedures indicated for the patient's neurological presentation, and significantly alter therapeutic recommendations for the brain tumor in $<10 \%$ of cases $(31,32)$.

Cross-sectional diagnostic imaging techniques, such as computed tomography (CT) and MRI have revolutionized the clinical diagnosis and management of brain tumors in veterinary medicine, although MRI is the preferred modality for the assessment of animals with intracranial disease (3353). Data obtained from MR imaging such as mass number (solitary vs. multiple), origin within the neuraxis (meningeal [extra-axial], parenchymal [intra-axial], or intraventricular) and intrinsic signal appearances, collectively provides characteristic patterns that allow for the presumptive diagnosis of most frequently encountered PBT and SBT in veterinary medicine or refinement of the list of differential diagnoses. The diagnostic imaging features of each of the common types of PBT are reviewed with their comparative neuropathologic features below. In one investigation of 40 dogs, the accuracy of predicting the type of PBT based on MR images was 70\% (44). It remains common in veterinary practice to make clinical decisions in patients with presumptively diagnosed tumors based on imaging derived data, despite the potential consequences this has on management of individual patients. There are also significant implications associated with the strength of evidence provided by studies that include cohorts of dogs without histopathologic tumor diagnoses.

Cerebrospinal fluid (CSF) analysis generally provides data that is complementary to the clinical examination and diagnostic imaging results and may assist in the prioritization of differential diagnosis. Obtaining CSF in dogs with brain tumors and intracranial hypertension carries a risk of causing clinical deterioration. Although this risk is low, it should be critically assessed in each patient and evaluated in context of the likelihood of obtaining a non-specific test result. Advanced imaging of the brain should always precede CSF collection to best evaluate individual patient risk.

While CSF is a sensitive indicator of intracranial disease and is frequently abnormal in patients with brain tumors, white blood cell (WBC) counts, WBC differentials, and total protein concentrations are highly variable and are often non-specific for neoplasia. There are conflicting data in the literature about the cytological characteristics of CSF in dogs with meningiomas, with one study reporting that meningiomas were commonly associated with a modest neutrophilic pleocytosis, and a later investigation concluding that the majority of meningiomas have WBC counts $<5$ cells, and a neutrophilic pleocytosis was an atypical finding for canine meningiomas located in the rostral or middle fossas $(54,55)$. In one study of CPT, CSF analysis was helpful for the differentiation of CPC from CPP, as observation of a CSF total protein concentration $>80 \mathrm{mg} / \mathrm{dL}$ was exclusively associated with a diagnosis of CPC (8). Exfoliated neoplastic cells may be observed in the CSF cytology of dogs with any type of brain tumor, but CPT, lymphoma, and histiocytic sarcoma are the tumors most commonly reported to be detected with CSF analysis $(3,8,56-58)$.

An evolving field in comparative medicine is the identification of circulating biomarkers in blood or CSF that correlate with brain tumor load, biological behavior, or treatment response. Liquid biopsy is a technique for sampling and analyzing nonsolid biological tissues, and is mainly used to diagnose disease or monitor therapy. Serum or plasma compounds such as VEGF, glial fibrillary acidic protein, plasma free amino acid profiles, and CSF concentrations of uric acid, D-dimers, and MMP-2 and MMP-9 have been quantified in dogs with brain tumors, but results to date suggest that these compounds will not fulfill ideal biomarker criteria due to limitations associated with sensitivity and specificity (59-65).

Circulating tumor DNA (ctDNA), circulating cell-free RNA, serum proteomic profiling, and exosomes are also currently being explored as liquid biopsy biomarkers in veterinary neurooncology $(66,67)$. Serum proteomic microarray profiles classified dogs as having intracranial neoplasia, meningoencephalitis of unknown etiology, or being healthy with $100 \%$ accuracy and preliminary data suggests that proteomic immunosignatures may also have utility in distinguishing tumor types (67). A feasibility study in canine glioma has demonstrated that expression of cell surface integrins $\alpha v \beta 3$ and $\alpha 3 \beta$ can be detected in canine glioma cell lines, as well as exosomes derived from these lines using integrin specific peptide targeting methods (66). This investigation provides the foundation for further exploration of serum and CSF exosomes as potential in vivo biomarkers of canine glioma.

Given the limitations of imaging, CSF analyses, and liquid biopsy techniques, histopathologic examination of representative tissue is required for the definitive diagnosis and grading of nervous system tumors. Excisional biopsy performed during curative intent surgery remains the most frequently employed biopsy technique for PBT in veterinary practice, but these procedures have been historically limited to patients with superficially located, extra-axial forebrain tumors. In cases where surgical resection may not be a possible or optimal approach to management, stereotactic brain biopsy (SBB) techniques are often a viable alternative method for establishing a histopathologic diagnosis. 
Several SBB techniques have been utilized in dogs with brain tumors including endoscopic assisted, free-hand, and imageguided procedures. SBB associated diagnostic yields, morbidity, and mortality are variable and dependent on the technique used, the neurologic status of the patient, experience of the surgeon, and the neuroanatomic location of the lesion (68-74). However, similar to the human experience, when SBB is performed in dogs with brain tumors by an experienced veterinary neurosurgeons, diagnostic yields are 95\%, and serious adverse events occur in $<5 \%$ of cases $(72,74)$. The histological classification and grading of CNS tumors can be challenging, especially when evaluating the limited sample sizes associated with SBB, but accurate diagnoses can be facilitated by taking multiple biopsy specimens $(72,74)$.

\section{GLIOMA}

\section{Diagnostic Imaging Features}

Gliomas originate within the brain parenchyma (intra-axial). As gliomas may infiltrate or displace the neuroparenchyma, they may appear poorly or well marginated and may or may not demonstrate contrast enhancement (Table 1) $(33,44,46,51,75)$. Among contrast enhancing gliomas, the patterns and degree of enhancement seen can be highly variable. A "ring enhancing" pattern, in which a circular ring of contrast enhancement surrounds non-enhancing abnormal tissue, is often associated with gliomas (Figure 1A). However, ring enhancement is a non-specific finding that has been associated with several neoplastic, vascular, and inflammatory brain diseases (35, 49). Using conventional MRI sequences, it is not currently possible to reliably differentiate types of gliomas (astrocytomas from oligodendrogliomas) or accurately predict the grade of gliomas. However, contrast enhancement is more commonly observed in high-grade compared to low-grade gliomas, and oligodendrogliomas are more likely to distort the ventricles and have contact with the brain surface than astrocytomas $(47,50$, 75). The significant overlap that exists in the imaging features of gliomas, cerebrovascular accidents, and inflammatory lesions results in frequent misdiagnosis of these categories of intraaxial lesions $(40,49)$. The addition of diffusion weighted (DWI), spectroscopic, and perfusion weighted imaging sequences to conventional MRI sequences improves the ability of MRI to discriminate between neoplastic and non-neoplastic lesions, and prediction of tumor grades. However, the utility of this suite of imaging techniques has not yet been evaluated in large populations of dogs with histologically confirmed lesions $(34,41-$ $43,45,48,53,76)$.

\section{Pathologic and Comparative Features}

The pathology underpinnings of canine glioma have undergone much development in the last several decades with advances in histologic interpretation, immunohistochemical profiling, and molecular diagnostics. Of the total glioma number, oligodendrogliomas have an incidence close to $70 \%$ with astrocytomas $\sim 20 \%$, and undefined 10\%. Grossly, oligodendrogliomas vary from well-demarcated white to tan, fleshy, soft masses (Figure 1B) to those that are more infiltrative in the neuroparenchyma. They are commonly gelatinous owing to a high level of mucin production. They can be found intraventricularly, multifocally within the central nervous system, or diffusely in the leptomeninges as either a primary mass or metastatic spread (77-79). Astrocytomas tend to be similar in color to the adjacent neuroparenchyma and often blend with the adjacent parenchyma without obvious mass formation (78). Undefined gliomas have a population of astrocytic and oligodendroglial differentiation that are roughly equivalent and therefore the gross features can include any or all of those noted above. For all of the three glioma subtypes in the dog, higher grade tumors are more likely to have associated hemorrhage. In some instances, calvarial bone erosion can be associated with glioma; however, this is not specific to glioma (80).

Historically, canine gliomas were defined based on the original World Health Organization criteria; however, this outdated classification scheme has been replaced by a more comprehensive grading system $(78,81)$. Based on the new histologic grading scheme, gliomas are divided into oligodendroglioma, astrocytoma, and undefined glioma based on their histomorphology (Figure 1C). Neoplasms are further divided into low- or high-grade. High-grade tumors are diagnosed based on any one of the following being present in the tumor sections examined: microvascular proliferation (Figure 1C, inset), intratumoral, geographic necrosis, pseudopalisading around the regions of necrosis (Figure 1D), increased mitotic activity, or overt features of malignancy (78). The degree of infiltration is not a criterion for differentiating low- vs. high-grade; however, the pattern (non-infiltrative, focally infiltrative, or diffusely infiltrative) should be noted when making the diagnosis (78). Readers are urged to review the updated histologic characterization criteria as an in depth discussion of histologic features are outside the scope of this review paper (78). However, generally speaking, oligodendrogliomas are composed of sheets and linear cords of round to polygonal cells with variable amounts of cytoplasm, round nuclei, and a finely stippled chromatin pattern (82). Especially in necropsy or poorly fixed samples, neoplastic cells often have abundant clear cytoplasm leading to a fried-egg appearance. This is a feature absent in biopsy samples due to timely and appropriate fixation. The formation of secondary structures (neuronal satellitosis, leptomeningeal spread, and perivascular proliferation) are commonly noted in canine oligodendroglioma (Figure 1E). Low-grade tumors often have a delicate meshwork of branching vasculature whereas high-grade tumors have marked vascular proliferation with a glomeruloid appearance (78). Other features that can be observed in canine oligodendroglioma nuclear molding, pseudorosettes, mineralization, and microcysts, which all occur regardless of grade (78).

Astrocytomas have distinct histologic features compared to oligodendrogliomas. High-grade astrocytomas are more frequently invasive than low-grade astrocytomas (78). Neoplastic astrocytes generally have variable amounts of eosinophilic cytoplasm, elongate to ovoid nuclei, with an open chromatin pattern. Various phenotypic features that can be observed histologically in canine astrocytomas include gemistocytic and pilocytic patterns (83). Similar to oligodendrogliomas, 
TABLE 1 | Magnetic resonance imaging features of common canine primary brain tumors.

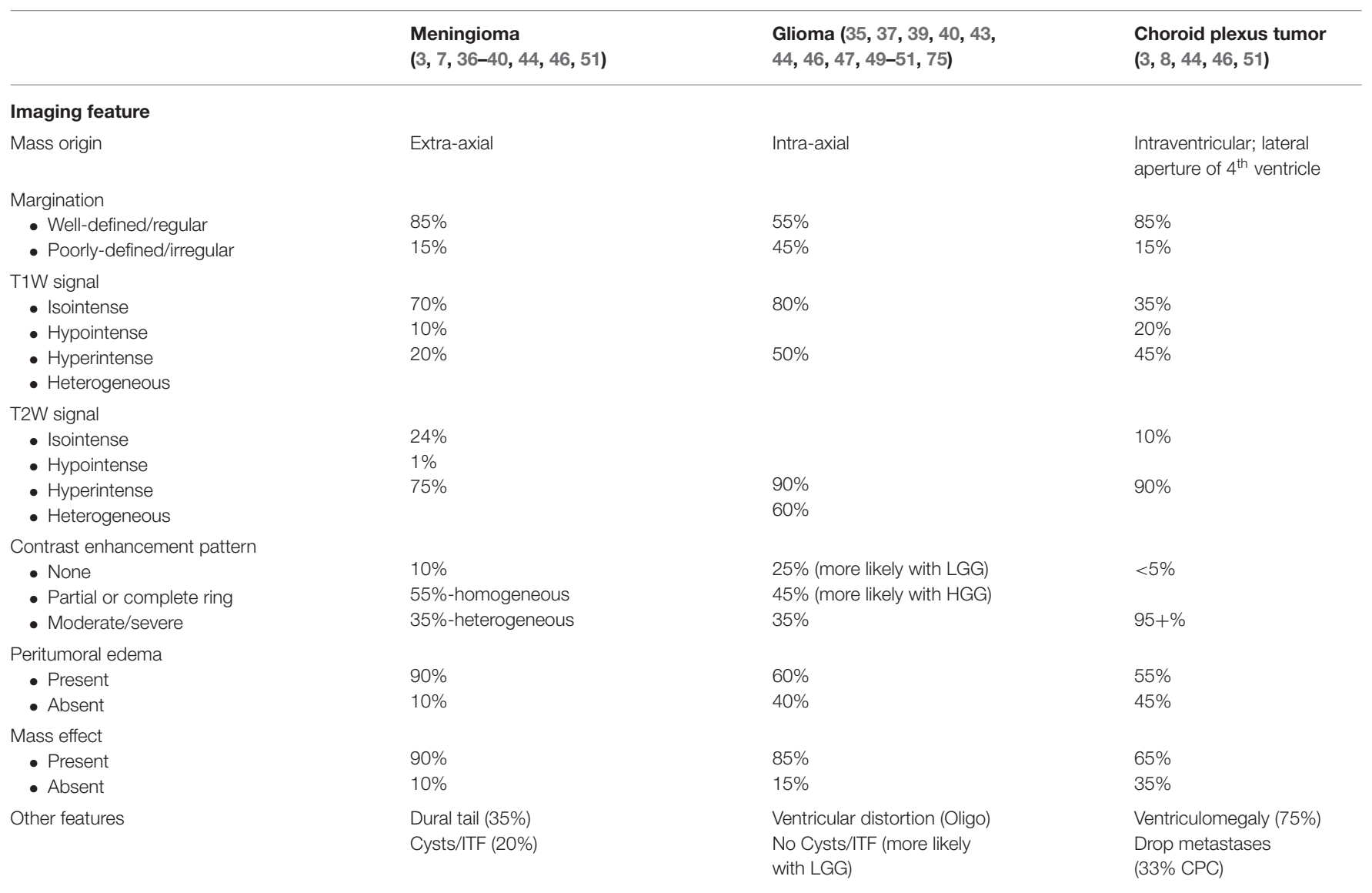

CPC, Choroid plexus carcinoma; HGG, high-grade glioma; ITF, intratumoral fluid; LGG, low-grade glioma; Oligo, Oligodendroglioma.

microcysts and mineralization can be observed and while rare deposits of mucin can be noted, they are never as abundant as they are in oligodendrogliomas $(78,82)$. A seemingly unique astrocytoma phenotypic variant has been observed in the cerebellum/caudal fossa in which tumors are well-demarcated and formed by sheets of gemistocyte-like cells (78). High-grade features are the same as those defined for oligodendroglioma and while the highest grade astrocytoma has traditionally been referred to as a glioblastoma, that term was replaced with the more encompassing high-grade astrocytoma in the most recent classification $(78,84)$. Undefined gliomas have any of the histologic features described above for oligodendroglioma and astrocytoma; however, the proportions of each are relatively equal thereby preventing classification into one group or the other.

Immunohistochemistry has been widely studied in canine glioma. For basic diagnostic purposes, immunolabeling for the glial cell transcription factor, Olig2, stains canine glioma effectively (Figure 1F). Its pattern of immunolabeling is most robust in oligodendrogliomas as opposed to astrocytic tumors where the staining intensity and percent of positive cells is decreased (78). Immunolabeling for glial fibrillary acidic protein (GFAP) is considered supportive of the diagnosis of astrocytoma whereas immunolabeling for CNPase is considered supportive of the diagnosis of oligodendroglioma (78). While
Ki67 has been utilized in canine glioma, its widely variable expression patterns in the face of expected staining patterns (i.e., in a tumor with markedly increased mitotic activity) questions its utility in these tumors. Importantly, all of the markers noted above are known to have marked variation in labeling patterns in necropsy samples (owing to variations in fixation time, autolysis, amount of formalin used, and other factors) and use of these markers in necropsy samples should be interpreted with caution (78). Immunohistochemical studies in canine oligodendrogliomas support that these tumors have a dedifferentiated phenotype, one that may arise from an oligodendrocyte precursor cell, perhaps specific to the subventricular zone (85). Some of the markers used to support the origin from oligodendrocyte precursor cells include SOX10, nestin, NG2, and doublecortin (85). In addition, canine gliomas express several neuronal markers including synaptophysin supporting an origin from a multipotential cell type (82). Utilization of tissue microarrays of canine glioma for immunohistochemistry has revealed overexpression of EGFR, PDGFR $\alpha$, IGFBP2 with EGFR expression moderately correlated to Ki67 immunoreactivity $(86,87)$. Neither COX-2 nor c-kit have been shown to be expressed in canine glioma (88). While isocitrate dehydrogenase 1 (IDH1) expression has been confirmed in canine glioma via immunohistochemistry, 

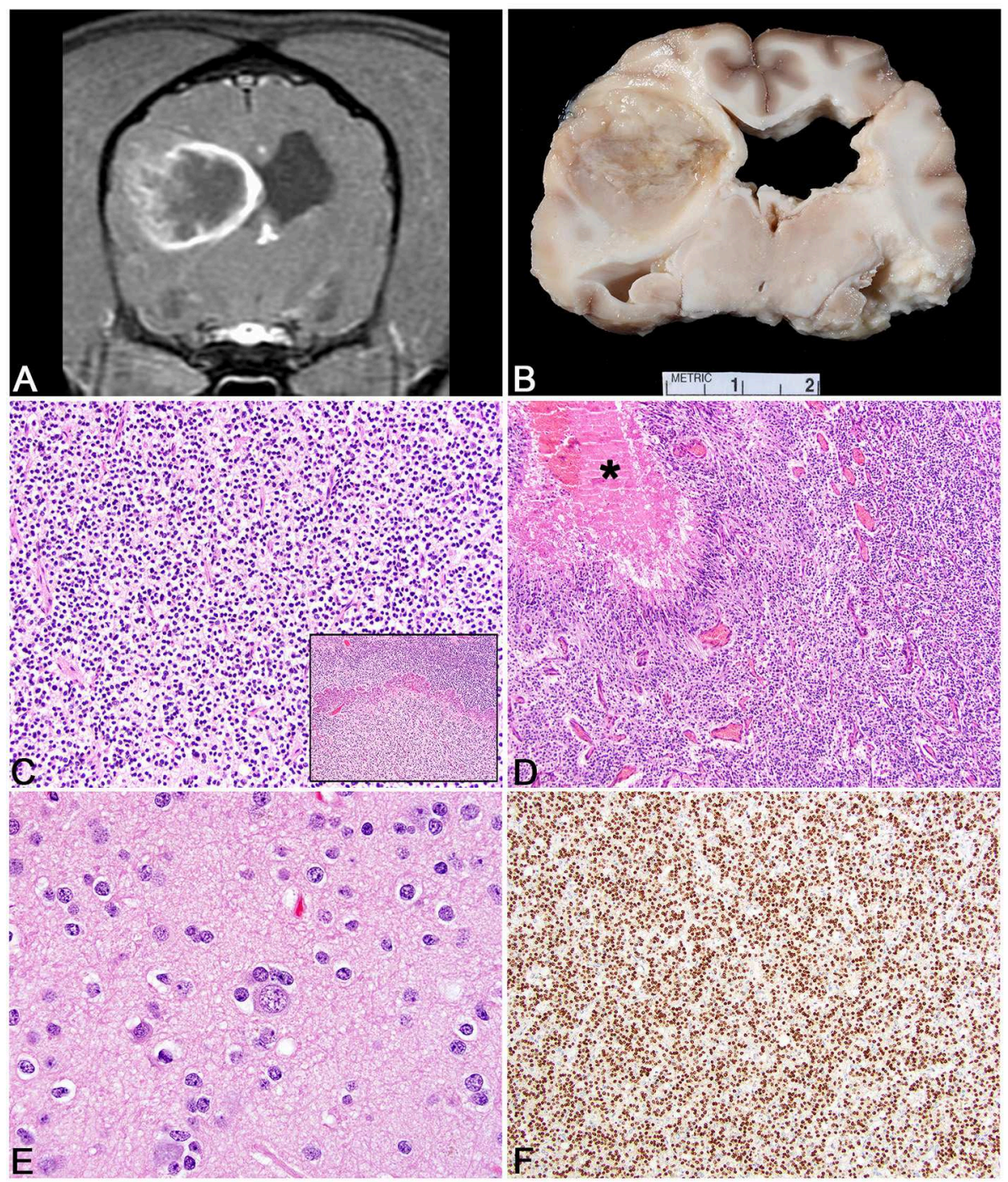

FIGURE 1 | Glioma. (A) Canine; MRI-High-Grade Oligodendroglioma. Transverse, post-contrast T1W image illustrating heterogeneously hypointense and ring-enhancing intra-axial mass in the right parieto-temporal lobes. The mass is markedly attenuating the right lateral ventricle. (B) Canine, High-Grade Oligodendroglioma. Corresponding necropsy specimen of (A) illustrating a well-demarcated mass is present in cerebral cortex causing compression of the thalamus and dilation of the lateral ventricles. (C) Canine, High-Grade Oligodendroglioma. Sheets of neoplastic oligodendrocytes embedded in a loose matrix. Hematoxylin and eosin (HE). Inset: Areas of microvascular proliferation. HE. (D) Canine, High-Grade Astrocytoma. Discrete areas of necrosis (asterisk) with pseuopalisading by neoplastic cells. HE. (E) Human, Grade II Oligodendroglioma. Abundant peri-neuronal satellitosis (secondary structure) is present in this neoplasm. HE. (F) Canine, High-Grade Oligodendroglioma. Diffuse intranuclear immunolabeling for Olig2 immunohistochemistry (IHC).

further genome analysis has failed to reveal consistent mutations within the gene as opposed to human gliomas where IDH1 mutation is a common finding (89). Lastly, the inflammatory microenvironment has begun to be explored in canine oligodendroglioma with neoplasms having a robust population of infiltrating $\mathrm{T}$ lymphocytes and macrophages (typically with a dendritic cell morphology) with far fewer B lymphocytes (90). Increased numbers of regulatory $\mathrm{T}$ cells and dendritic cells have also been recorded in the peripheral blood of canine glioma patients (91). Canine gliomas express PD-L1 which may directly relate to the inflammatory milieu present in these patients (91).
Our understanding of the molecular pathogenesis of canine glioma has also greatly expanded in the last few years. Cell lines generated from canine glioma support multipotentiality in these tumors (92). A wide-ranging genomic profiling of canine glioma has been occurring in parallel with the histologic reclassification of canine glioma. This molecular analysis has confirmed some previous reports in the literature and revealed frequently occurring mutations in the p53 pathway, CDK4, CDKN2A, EGFR, and PDGFRA (93-95). PDGFRA is an especially attractive driver mutation as it is expressed in neural stem cells and known to be critical to gliomagenesis; however, it remains to be determined how it exactly exerts its effects in 
the development of glioma. Specific to the p53 pathway, TP53 protein is commonly recognized in canine astrocytic tumors compared to oligodendrogliomas with more variable expression of MDM2 and p21 noted across the other glioma tumor types (93). Phosphorylated members of the PI3K/AKT/MTOR and RAS/MAPK-pathways are seen more commonly in astrocytic tumors than oligodendrogliomas or undefined gliomas (93, 96). When canine and human glioma molecular signatures are compared, it is clear that there is an abundance of heterogeneity amongst these two species as it relates to gliomagenesis (97). $1 \mathrm{p} / 19 \mathrm{q}$ co-deletion, which is common in human gliomas, is absent in the dog $(94,95)$. Similarly Tert promotor mutations are lacking and while R132 mutations of IDH1 have been noted rarely in canine glioma, they do not appear to have a cancerpromoting effect like they do in human glioma $(94,95)$. Much work remains in determining the molecular pathogenesis of canine glioma and its application to glioma prognosis in the dog.

Histological classification of human gliomas has had a long history (98). Yet each iteration that was based solely on microscopic morphology suffered from intra- and interobserver variability that contributed to prognostic imprecision and negatively impacted treatment decision-making (99, 100). Indeed, microscopic discrimination of astrocytomas from oligodendrogliomas has long proven difficult, even for experienced neuropathologists $(101,102)$.

The 2007 World Health Organization (WHO) classification was the last to rely solely on microscopy to subdivide tumors into astrocytomas, oligodendrogliomas, or (mixed) oligoastrocytomas. Grading was based on morphological features such as mitoses, microvascular proliferation, and necrosis. Their presence correlated strongly with aggressive biology and permitted diagnostic refinement into seven distinct prognostic entities (98). Comprehensive molecular analyses have transformed contemporary tumor classification schemes. Studies have clearly established that significant intertumoral molecular heterogeneity exists among each of the morphologically-defined diffuse gliomas $(103,104)$.

Discovery of mutations in isocitrate dehydrogenase 1 (IDH1), which encodes a metabolic enzyme involved in the tricarboxylic acid cycle, significantly altered the trajectory of diagnostic neuropathology and laid the groundwork for the 2016 WHO classification update, particularly for lower-grade (WHO grades II and III) gliomas (105). Subsequent studies identified mutations in either $I D H 1$ or $I D H 2$ in over $70 \%$ of lower-grade gliomas, as well as a small subset $(\sim 5 \%)$ of secondary glioblastomas that evolved from lower-grade precursors (106). IDH1/2 mutations were found in both astrocytomas and oligodendrogliomas and portended a better outcome that IDH1/2-wild-type (wt) tumors.

Oligodendrogliomas have been known for several decades to feature a recurrent genetic mutation, loss of chromosomes $1 \mathrm{p}$ and $19 \mathrm{q}$, which correlates with improved prognosis and response to therapy $(107,108)$. Comprehensive genomics and integrative bioinformatics studies solidified its role in contemporary human glioma classification. A population-based study that analyzed 3 molecular markers (1p/19q, IDH1/2, and TERT promoter) stratified grade II and III gliomas into five molecular subgroups independently associated with clinical outcomes (109). A
TCGA lower-grade glioma study used comprehensive multiple omics data and unbiased integrative bioinformatics analyses to define three molecular subtypes based on two molecular markers, $1 \mathrm{p} / 19 \mathrm{q}$ codeletion and IDH1/2 mutations (110). Importantly, each subtype-IDHmt lacking $1 \mathrm{p} / 19 \mathrm{q}$ codeletion, IDHmt with $1 \mathrm{p} / 19 \mathrm{q}$ codeletion, and IDHwt-were prognostically significant and non-overlapping. Half of patients with $1 \mathrm{p} / 19 \mathrm{q}-$ codeleted tumors survived 8.0 years, IDHmt, non-codeleted tumors 6.3 years and IDHwt tumors 1.7 years. Most IDH-mt tumors without codeletion were histological astrocytomas, and nearly all featured mutations in TP53 and ATRX. Most IDH$\mathrm{mt}$ tumors with codeletion were histological oligodendrogliomas and harbored CIC, FUBP1, NOTCH1, and TERT promoter (TERTp) mutations. These data confirmed previous reports identifying CIC and FUBP1 as candidate oligodendroglioma tumor suppressor genes lost on chromosomes $1 \mathrm{p}$ and $19 \mathrm{q}$ respectively (111). Other large studies have reported similar findings $(112,113)$.

A significant fraction of WHO grade II/III gliomas lack IDH mutations, especially grade III tumors with astrocytic histology (114). These tumors frequently harbor molecular alterations typically seen in WHO grade IV glioblastomas, including chromosome 7 gains, chromosome 10 deletions, EGFR amplification, TERTp mutations, and deletions of CDKN2A. The prognosis of these IDHwt tumors is worse than their corresponding IDHmt counterparts. The unfavorable prognosis is particularly strong for IDHwt anaplastic gliomas (114). In this study, IDHwt tumors were further divided into a molecularly unfavorable group (those having either EGFR amplification, H3F3A mutation, or TERTp mutation) and a favorable group lacking those alterations. A subsequent TCGA analysis of both lower-grade glioma and glioblastoma datasets showed that IDHwt lower-grade gliomas segregated into three DNA methylation subtypes (115). Two harbored glioblastomalike mutations, including EGFR, PTEN, and NF1. The third methylation subtype shared mutational similarities to the nondiffuse glioma, pilocytic astrocytoma (WHO grade I), and portended a similarly favorable prognosis.

Based largely on these studies, the 2016 WHO classification of human gliomas represented a nosological shift in focus away from diagnoses based solely on morphological criteria to one of integrative diagnoses based on both phenotype and genotype (116). Six diagnostic entities were established, each with a required molecular marker (Table 2). With increased interest in canine glioma and larger molecular studies being performed in these tumors, it is logical that molecular classification will be layered onto the newly revised histologic classification to create a more detailed stratification of canine glial tumors.

\section{MENINGIOMA}

\section{Diagnostic Imaging Features}

Meningiomas are the most common extra-axial meningeal origin tumors in dogs (Table 1). Although most meningiomas occur as solitary masses, multiple tumors can be seen (27). Meningiomas usually have a broad-based attachment where they interface with the skull, have distinct tumor margins, and demonstrate marked 
TABLE 2 | Current classification scheme of human glioma.

\begin{tabular}{lll}
\hline WHO grade & $\mathbf{2 0 0 7}$ WHO & $\mathbf{2 0 1 6}$ WHO \\
\hline II & $\begin{array}{l}\text { Diffuse astrocytoma } \\
\text { Oligoastrocytoma } \\
\text { Oligodendroglioma }\end{array}$ & $\begin{array}{l}\text { Diffuse astrocytoma, IDH-mutant } \\
\text { Oligodendroglioma, IDH-mutant } \\
\text { and 1p/19q codeleted }\end{array}$ \\
An II & Anaplastic astrocytoma & Anaplic astrocytoma, \\
& Anaplastic oligodendrogliomas & Anaplastic oligodendroglioma, \\
& & IDH-mutant and \\
& & $1 \mathrm{p} / 19 \mathrm{q}$ codeleted \\
& & Glioblastoma, IDH-wildtype \\
IV & Glioblastoma, IDH-mutant \\
&
\end{tabular}

and often uniform contrast enhancement (Figure 2A). Some meningiomas will also contain intratumoral fluid, large cystic regions, intratumoral mineralization, calvarial hyperostosis, or demonstrate a dural tail sign $(36,38,46,51)$. Although the dural tail feature is commonly associated with meningiomas, it is not specific for this tumor type, or for neoplastic diseases in general $(38,40)$. Peritumoral edema is present in $>90 \%$ of canine meningiomas, and is extensive and diffuse in many cases $(7,44,46)$. In dogs, reported sensitivities of MRI to correctly identify intracranial meningiomas range between 60 and 100\% $(3,35,37,39,44)$. Histiocytic sarcomas and granular cell tumors share many overlapping imaging features significant with those of meningiomas $(46,51)$. Specific subtypes of meningiomas cannot be distinguished using conventional MRI sequences (7), although quantitative radiomic analyses has shown some promise in discriminating grades of meningiomas (52).

\section{Pathologic and Comparative Features}

As noted, meningiomas are the most common primary brain and spinal cord neoplasm in the dog. These tumors arise from the arachnoid cap cells that line the middle layer of meninges. They are an intradural, but extraparenchymal solitary neoplasm of which their incidence decreases caudally through the central nervous system, perhaps due to a decreased density of arachnoid cells. Grossly, they tend to be firm, multilobulated, gray to white masses that are compressive and variably infiltrative (Figure 2B). Less common manifestations include a broad, en plaque presentation, in which the meningioma spreads over a large area of the brain and is commonly infiltrative into the adjacent neuroparenchyma. This less common pattern most often presents around the ventral portion of the brainstem, especially along the skull base (117). While they can often be locally infiltrative, spread within the central nervous system is not well recorded in the literature and metastatic spread to extra-CNS organs is an exceedingly rare event (118).

Based on their location, they are one of the few primary brain tumors that can be amenable to surgical excision and owing to their complex origin from neural crest cells and mesoderm, they exhibit a vast array of histologic patterns that correlate well to similar patterns seen in human meningioma. The World Health Organization (WHO) histologic classification scheme of canine meningioma recognizes two broad categories: slow-growing, generally benign neoplasms (which represents a number of subtypes: meningothelial, fibrous, transitional, psammomatous, angiomatous, myxoid, granular, and papillary) and more anaplastic tumors which generally don't have as much benign behavior (81). However, it must be stressed that the canine classification scheme is greatly outdated, and much work remains to be done to develop a canine classification scheme that can be correlated with and predict biologic behavior. In comparison, the human classification scheme is vastly more advanced (116). Indeed, many veterinary pathologists have resorted to using the human criteria for grading canine meningiomas due to a lack of adequate canine grading criteria (7). While the 2016 WHO classification of human meningiomas continues to rely solely on microscopic morphology, molecular analyses coupled with detailed histologic analysis are poised to revolutionize classification of these neoplasms. Such advances promise better determination of tumor behavior and patient outcome.

The most common histologic subtypes of canine meningioma are meningothelial, fibroblastic, transitional, and atypical. Meningothelial meningiomas are formed by sheets of meningothelial cells often with vague whorling (Figures 2C,D). Cells typically have abundant cytoplasm, large round to ovoid nuclei with an open chromatin pattern and a single, often prominent nucleolus. The nuclear features are especially well conserved across different subtypes and can be helpful in guiding the diagnosis on less common subtypes. Fibroblastic meningiomas consist of streams of spindle cells with abundant collagen deposition. The transitional subtype combines the feature of the meningothelial and fibrous subtypes such that both patterns are a significant portion of the neoplasm (Figure 2E). A further subtype of the transitional meningioma is the psammomatous meningioma, so named based on the abundant mineralized concretions that are present in the center of meningothelial whorls. This subtype should only be diagnosed if the psammoma bodies are the predominant histologic pattern as small numbers of psammoma bodies can be found in many subtypes of canine meningioma. Meningothelial and transitional subtypes represent anywhere from 20 to $30 \%$ or higher of meningioma incidence (119). Microcystic meningiomas are also a relatively common subtype in the dog and have large, variably sized vacuoles that develop in the neoplastic cells that can often coalesce to form large cysts within the tumor (120). In this rare instance, the gross texture of a microcystic meningioma is more fluctuant than the more common firm texture. Importantly, the microcystic subtype should only be designated if this is the predominant pattern as focal to multifocal microcystic change is common in many subtypes of canine meningioma. The granular cell subtype of meningioma consists of large meningothelial cells with abundant periodic acid-Schiff positive granules within the cytoplasm. It remains to be determined if the granular cell variant of canine meningioma is distinct from the intracranial granular cell tumor in the dog; however, it is likely that they represent the same entity as meningothelial whorls can be found in granular cell tumors of the canine CNS with methodical histologic analysis (121).

Other histologic subtypes include rhabdoid meningioma, which has meningothelial cells with abundant eosinophilic 

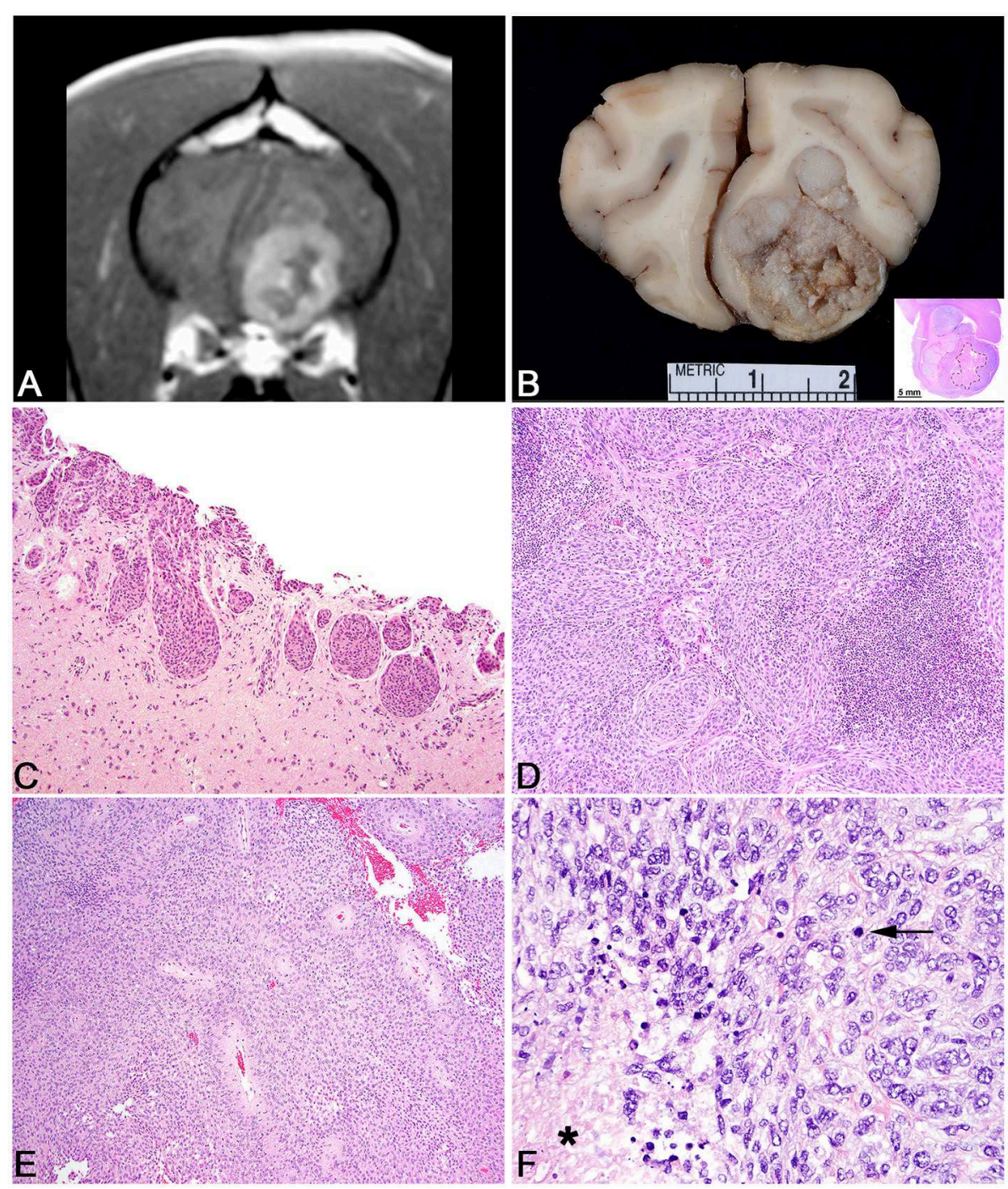

FIGURE 2 | Meningioma. (A) Canine; MRI. Transverse, post-contrast T1W image of a well-demarcated, ring-enhancing extra-axial mass in the ventral aspect of the left frontal lobe. Mass effect is present as manifested by the falx shift to the right. (B) Canine, Meningioma. Corresponding necropsy specimen of (A) illustrating a large, multilobular, white to tan mass that invades the neuroparenchyma. Inset: subgross histologic representation of the meningioma characterized by peripheral sheets of meningothelial cells centered on a core of necrosis. Hematoxylin and eosin (HE). (C) Canine, Transitional Meningioma, Invasive. Markedly invasive whorls and clusters of neoplastic meningothelial cells. HE. (D) Canine, Transitional Meningioma. Tightly packed whorls and clusters with an associated focus of neutrophils. HE. (E) Canine, Meningothelial Meningioma. Sheets of meningothelial cells that surround blood vessels with an acellular perivascular halo. HE. (F) Human, Anaplastic Meningioma. Large area of necrosis (asterisk) with sheets of meningothelial cells with increased mitotic figures (arrows). HE.

cytoplasm and small, peripheralized nuclei. Papillary subtypes are defined by an abundance of pseudorosettes (122). While this can be the predominant histologic pattern, papillary change can also be a focal change within a meningioma. Although suggested by the WHO canine criteria as being a more benign variant, data supports that these are often aggressive subtypes of canine meningioma with a high degree of recurrence (122). This suggests a more malignant behavior for these tumors in the dog, which would be analogous to the human papillary subtype (122). Angiomatous meningiomas are uncommon and represent a meningioma that is highly vascularized. Atypical meningiomas have any of the features noted above, but also have increased mitotic activity ( $>4$ mitoses per ten $400 \mathrm{x}$ fields) or have three or more of the following: increased cellularity, increased anisocytosis and anisokaryosis, patterned necrosis, or patternless growth patterns (7). It must be noted, that in canine meningioma, regions of necrosis are common and should not be over interpreted as always indicating an atypical subtype. While the cut off for mitotic count at 4 in ten $400 \mathrm{x}$ fields is based on the human WHO meningioma criteria, it remains to be determined if this is an appropriate cut off for canine meningioma or if a better determination of mitotic activity (i.e., Ki67 or AgNOR) is more predictive. Based on some canine studies, the incidence of atypical meningiomas reaches $\sim 40 \%$, a percentage that far 
outpaces the incidence of human atypical meningiomas (7). Lastly anaplastic meningiomas represent a very uncommon diagnosis in the dog and have greatly exaggerated features of malignancy compared to the atypical variant (Figure 2F).

Other histologic features of importance in the dog include rare deposition of amyloid and exceedingly rare formations of amianthoid fibers (123). Canine meningiomas are widely infiltrated by inflammatory cells including an abundance of neutrophils, either associated with or unassociated with areas of necrosis, large numbers of macrophages and an abundance of lymphocyte subtypes (124). Initial immunohistochemical analysis for interleukin 6 and 8 expression failed to yield significant expression levels; however, RNA transcriptome analysis of canine meningioma revealed overexpression in a number of immunomodulatory genes $(125,126)$. Chondroid and osseous metaplasia are sporadically seen in various subtypes, although they are most commonly seen in the optic nerveassociated meningiomas.

Owing to their diverse embryologic origin, it is not surprising that canine meningiomas have recorded immunoreactivity to a wide number of antibodies, none of which are specific to the diagnosis of a meningioma. Diagnosis of a meningioma still relies predominately on histologic analysis even though it can be augmented by specific immunohistochemical assays. Canine meningiomas are almost always positive for vimentin and also commonly express laminin, NSE, E-cadherin, CD34, GLUT-1, claudin-1, PGP9.5, pancytokeratin, and $\operatorname{S100}(127,128)$. The combination of immunolabeling for vimentin, CD34, and Ecadherin has been proposed as being supportive of the diagnosis of meningioma (127). Additional studies on cell adhesion molecules in canine meningioma has revealed that $\mathrm{N}$-cadherin expression is directly correlated with an invasive phenotype (129). This N-cadherin expression is joined by expression of doublecortin at the invading line of the meningioma as well as increased nuclear $\beta$-catenin, all three of which may hold prognostic value for more aggressive meningiomas (129). Progesterone receptor expression has been noted in canine meningiomas, where it is inversely related to Ki67 and a better response to radiation therapy $(130,131)$. Estrogen receptors are less commonly expressed in canine meningiomas (131).

Vascular endothelial growth factor (VEGF) expression has been studied to some detail in the dog. Various isoforms have been identified in the dog and expression of VEGF in both the meningiomas and plasma from affected patients is related to increased tumor malignancy and a poorer prognosis $(60,132$, 133). VEGF expression has not been correlated to proliferation indices nor has it been correlated to peritumoral edema (133, 134). Matrix metalloproteinases have also been a common avenue of exploration in the dog. MMP-2 and - 9 are widely expressed in canine meningioma; however, expression is not correlated with peritumoral edema $(135,136)$. Additionally, tissue inhibitors of metalloproteinases are also expressed in canine meningioma and is highest in papillary subtypes where it and a similar increase in MMP-2 expression may be associated with the more aggressive phenotype seen in this subtype (137). Human-telomerase reverse transcriptase expression has been described in a number of canine meningioma subtypes; however, has not been evaluated in a prognostic setting (138). Somatostatin receptor-2 expression has recently been described in a variety of canine meningioma subtypes, a finding that is supported by RNAseq data analysis of canine meningioma that revealed increased expression of somatostatin receptors $(126,139)$. The significance of this finding is unclear; however, similar findings have been noted in a number of human tumors, including meningioma. Folate receptor- $\alpha$ is also overexpressed in canine meningioma, as it is in human meningioma (140).

In depth transcriptome-level analysis of canine meningioma remains in its infancy. Analysis of formalin-fixed, paraffin embedded canine meningioma tissue has proven feasible and yielded significant data to suggest a wide variety of intratumoral abnormalities (126). Underexpressed genes included those associated with tumor suppression and cell adhesion among others (126). Real-time reverse-transcription polymerase chain reaction (RT-PCR) studies do not support significant alterations in NF2 in the dog compared to human cases (141). Western blot analysis has revealed that dogs have decreased expression of tumor suppressor genes $4.1 B$ and TSLC1; however, additional studies are needed to determine the functional significance of these abnormalities (141). Owing to the relative ease of biopsy sampling for many canine meningiomas, the field is primed to better define the molecular pathogenesis of this common canine tumor.

Like gliomas, histological classification of human meningiomas has had a long history (116). However, microscopic morphology remains the foundation of diagnosis and prognostication of these tumors. Indeed, the 2016 WHO classification included only one addition to its 2007 predecessor: the introduction of brain invasion as an independent diagnostic criterion for atypical (WHO grade II) meningiomas (116). This inclusion has significant implications for its usage in canine meningioma as a significant number of canine meningiomas are invasive even without other atypical features. These tumors continue to be stratified into three histological grades (WHO grade I-III) with increased biological aggressiveness and worse prognosis.

The majority of human meningiomas are benign, slow growing, low grade (WHO grade I) lesions. Nine distinct variants of grade I tumors are recognized histologically: meningothelial, fibrous, transitional, psammomatous, angiomatous, microcystic, secretory, lymphoplasmacyterich, and metaplastic meningiomas. All have similar prognosis. WHO grade I meningiomas are distinguished from their benign counterparts on the basis of morphological features or patterns. Atypical meningiomas (WHO grade II) feature one of the nine histological patterns listed above, but also harbor increased mitotic activity ( $>4$ mitoses per 10 high-powered fields), brain invasion, or at least three of the following "soft criteria:" increased cellularity, small cell change, prominent nucleoli, sheeting architecture, or necrotic foci. Two histological variants are also considered WHO grade II: clear cell and chordoid meningiomas. Each of these intermediate grade meningiomas portends an increased risk of recurrence (116). The most malignant meningiomas correspond to WHO grade III. These include anaplastic (malignant) meningiomas, which feature 
overtly malignant cytology (resembling carcinoma, melanoma, or sarcoma) or histological patterns of their lower-grade counterparts with significantly increased mitotic activity $(>20$ mitoses per 10 high-powered fields). Two histological variants are also considered WHO grade III: papillary and rhabdoid meningiomas. Taken together, these tumors constitute $1-3 \%$ of all meningiomas and can be rapidly fatal. Extent of surgical resection is the most significant prognostic factor.

The molecular pathogenesis of meningioma in humans is better understood than in the dog. There is an association between patients that have neurofibromatosis type 2 and the development of meningioma due to variable mutations in the NF2 gene and the subsequent production of a non-functional protein known as merlin (142). Although NF2 clearly illustrates that there are familial inheritance tendencies for meningioma, the majority of meningiomas in humans occur as sporadic tumors. Non-NF2 associated meningiomas are prone to a wide variety of mutations, many of which remain to be discovered. Known mutations in genes including AKT1, TRRAF7, KLF4, and $C D K N 2 A$ predispose to meningioma, including high grade meningiomas in the human WHO grading scheme (143).

\section{CHOROID PLEXUS TUMORS}

\section{Diagnostic Imaging Features}

Choroid plexus tumors are the most common tumors found in an intraventricular location and these tumors types often demonstrate marked contrast enhancement following gadolinium administration (Figure 3A) (Table 1) (8, 46). Other intraventricular tumors that are occasionally or rarely seen include ependymomas, oligodendrogliomas, primitive neuroectodermal tumors, and central neurocytoma $(3,46,51)$. The identification of intraventricular or subarachnoid metastatic tumor implants on MRI studies is a reliable means to clinically discriminate Grade III choroid plexus carcinomas (CPC) from Grade I papillomas (CPP) (8). While MRI is sensitive for the detection of intracranial neoplasms, a normal MRI does not rule out a brain tumor. Lymphomatosis and diffuse glioma (gliomatosis cerebri) are notable for their propensity to be occult on imaging studies of the brain.

\section{Pathologic and Comparative Features}

Choroid plexus tumors are intraventricular neoplasms that occur most commonly in the lateral and 4th ventricles, with a decreased incidence in the rest of the ventricular system. Grossly, the tumors are fleshy with a characteristic finely cobblestoned appearance that is gray to tan on section and variably invades the adjacent parenchyma (Figure 3B). Secondary hydrocephalus is a common accompanying feature due to obstruction of the ventricular system. Tumors are divided into papilloma, atypical papilloma, and carcinoma; however, the determination between the two can be difficult depending on the section examined and neoplasms with a benign histologic characteristics can nevertheless have parenchymal and distant spread. No accepted canine grading scheme is currently used and therefore tumors are commonly graded by the WHO human choroid plexus tumor criteria. The diagnosis of carcinoma is best based on the presence of desmoplasia, microvascular proliferation (which is rare in choroid plexus carcinomas compared to gliomas), and other overt malignant features like high mitotic rate, marked atypia, and patterned regions of necrosis (144). While vascular invasion and extraneural spread are not a feature of choroid plexus carcinoma, they will seed throughout the ventricular system where they are associated with carcinomatosis in the cerebral spinal fluid and can cause a mass effect at sites distant from the primary location (145).

Histologically, tumors typically form papillary and frondlike arborizing cords and trabeculae supported by a variably dense fibrovascular stroma (Figures 3C-E). Less commonly, areas of more sheet-like growth admixed with pseudorosettes can be found in these tumors (146). Unless invasion into the adjacent parenchyma is present, there are generally few changes in the adjacent tissue and often limited to mild gliosis and edema. Hemorrhage is not typically a feature of this neoplasm. Cells are arranged in simple to multilayered trabeculae with a variable chromatin pattern and typically a single, often inapparent, nucleolus. The mitotic count as determined by histologic examination as well as immunolabeling with Ki67 is highest in carcinomas (144).

While the histologic appearance of these tumors is generally characteristic, they can be mistaken for a metastatic carcinoma on biopsy. Immunohistochemical detection of Kir7.1, an inwardly rectifying potassium channel that has been shown to be a marker for human choroid plexus tumors, will stain the apical portion of neoplastic choroid plexus cells in the dog and can be used as a specific marker to differentiation choroid plexus tumor origin from other carcinomas that may have metastasized to the central nervous system (Figure 3F) (147). Pan-cytokeratin (CKAE1/3) expression is diffuse in choroid plexus tumors (148). E-cadherin and $\beta$-catenin labeling are commonly observed in canine choroid plexus tumors and can be associated with aberrant cytoplasmic or nuclear localization (149). While E-cadherin labeling does not vary between benign and malignant CPTs, the related protein $\mathrm{N}$-cadherin has been shown to be localized more commonly to choroid plexus papillomas than carcinomas (150). Immunolabeling for glial fibrillary acidic protein (GFAP) has also been recorded in canine CPTs; however, this is not a specific marker of choroid plexus cells (149). Vascular endothelial growth factor (VEGF), platelet-derived growth factor and it associated receptors, PDGFR $\alpha$, and PDGFR $\beta$ exhibit labeling commonly in $\mathrm{CPT}$ regardless of the designation of papilloma or carcinoma (144). Doublecortin labeling has not been recorded in these tumors (150).

The underlying molecular pathology of canine choroid plexus tumors remains poorly understood and an area ripe for further study. In the largest study to date, comparative cytogenic analysis of human and canine choroid plexus tumors revealed chromosomal losses in a number of chromosomes, including regions that included genes for TP53 and (151). Additional studies including regions that encode for tumor suppression and chromosomal instability genes transcriptome analysis of CPTs to normal canine choroid plexus are needed to better elucidate the underlying molecular mechanisms 


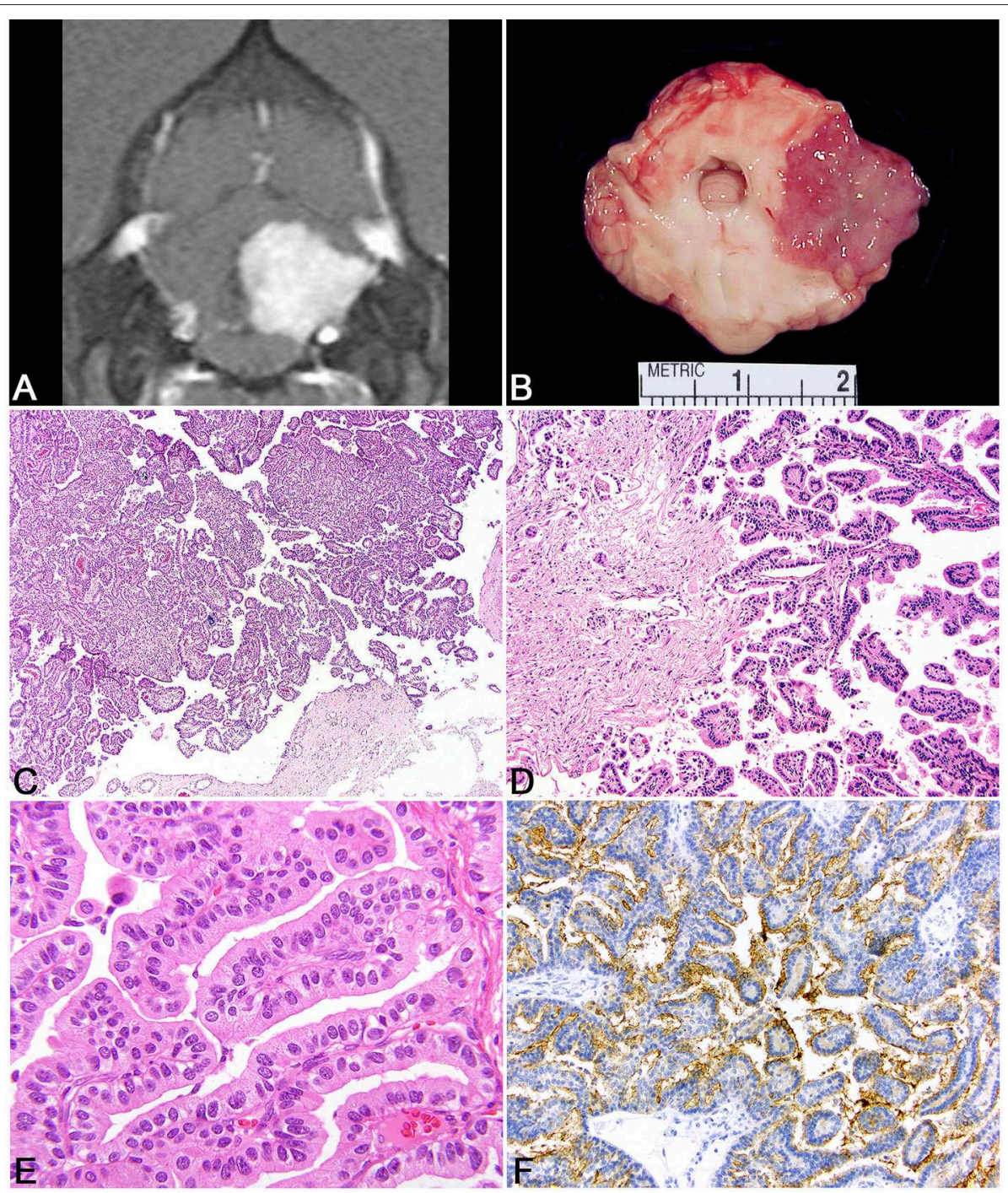

FIGURE 3 | Choroid plexus tumor. (A) Canine; MRI. Transverse, post-contrast T1W image demonstrating a uniformly and markedly enhancing, sharply defined mass lesion in the lateral aperture of the 4th ventricle causing compression of the overlying cerebellum. (B) Canine, choroid plexus tumor. Corresponding necropsy specimen of (A) illustrating a tan, fleshy, slightly granular neoplasm arising at the level of the lateral aperture. (C) Canine, choroid plexus tumor. Arborizing trabecular and papillary fronds lined by a single layer of choroid plexus epithelium. Hematoxylin and eosin (HE). (D) Canine, Choroid Plexus Carcinoma. Marked invasion into the underlying neuroparenchyma by tubular-like structure of choroid plexus epithelium. HE. (E) Human, Choroid Plexus Papilloma. Ribbons, cords, and papillary fronds of choroid plexus epithelium. HE. (F) Canine, Choroid Plexus Papilloma. Robust surface immunoreactivity for Kir7.1. Immunohistochemistry (IHC).

of these tumors and their potential as a comparative oncology model.

Choroid plexus tumors are uncommon in humans, although they are most commonly observed in children. As noted above, the histologic criteria are defined based on the WHO classification scheme which divides these tumors into three variants: papilloma, atypical papilloma, and carcinoma. Due to the uncommon nature of these tumors, most human studies concentrate on the histologic and immunohistochemical features of these tumors and genomic analysis is less well characterized although a significant number of choroid plexus carcinomas harbor TP53 mutations (116).

\section{CONTEMPORARY TREATMENT OF PBT IN VETERINARY MEDICINE}

Studies regarding the treatment of canine brain tumors are frequently limited by the inclusion of presumptively diagnosed cases, variable survival definitions and end-points, lack of inclusion of control groups, no reporting of objective imagingbased criteria of therapeutic response or other quantitative follow-up metrics, retrospective study designs, and small case numbers (152-154). Thus, there currently exists a considerable void in the literature with respect to clinically relevant data regarding tumor type-specific therapeutic outcomes for canine 
PBT, as well as a lack of adequately powered and rigorously designed trials comparing treatment modalities.

\section{Palliative Care and Watchful Monitoring}

The goal of palliative care is to improve the quality of life of patients and their caregivers through the identification, assessment, and treatment of pain and other physical or behavioral manifestations of the brain tumor. The primary pharmacologic palliative therapies administered to brain tumor patients are anticonvulsant drugs (ACD) for tumor-associated structural epilepsy, corticosteroids targeting peritumoral vasogenic edema, and analgesics for signs consistent with somatic, visceral, or neuropathic cancer pain $(21,152,153)$. Although seizures are one of the most common clinical signs associated with brain tumors, ideal ACD protocols for the treatment of tumor-associated epilepsy are currently unknown $(3,21)$. Phenobarbital, levetiracetam, and zonisamide are popular clinical ACD monotherapy choices. Multidrug ACD protocols are frequently needed to control refractory seizures in dogs with PBT, and the aggressiveness and diligence of the clinician's approach to seizure management is often as important to the therapeutic outcome as the patient's tumor response to other treatment modalities.

Animals that have peritumoral vasogenic edema on MRI are more likely to respond favorably to corticosteroid treatment. However, animals without significant edema may benefit also from the anti-inflammatory and euphoric effects of corticosteroids, and corticosteroid therapy alone may also transiently reduce the tumor volume in some cases $(21,152)$. Corticosteroids may also provide benefit to animals with tumors causing secondary obstructive hydrocephalus, although surgical CSF diversion via placement of an intraventricular shunt is a more effective method of alleviating clinical signs of intracranial hypertension from obstructive hydrocephalus (155). Polyuria, polydipsia, polyphagia, and sedation are commonly anticipated and reported adverse effects of palliative treatment, but palliative therapies are rarely associated with significant morbidity that necessitates discontinuation of therapy $(21,154)$.

Pain arising from nervous system tumors can arise from compression or stretching of the meninges, nerve roots, or vasculature, tumor-associated meningitis, neuritis, or radiculitis, and tumor infiltration of the periosteum or musculature. Hyperesthesia of the head or neck is occasionally observed in dogs with brain tumors, being reported in $12 \%$ of dogs with PBT in one study (3). Clinical signs consistent with pain often respond to corticosteroid treatment, and additional narcotic or neuropathic pain agents can be added as indicated (156).

Up of $6 \%$ canine intracranial meningiomas are identified incidentally (3). Given the increasing clinical usage of serial cross-sectional imaging techniques to manage numerous diseases in veterinary medicine, it is likely that the frequency of identification of incidental brain tumors will increase. Objective observation (e.g., watchful monitoring) represents another reasonable approach to the management of some small and asymptomatic brain tumors. Further characterization of the natural disease history for specific brain tumors will be paramount to identifying optimal indications for watchful monitoring, as well as recommended observation intervals and protocols.

Currently, there is no robust data regarding survival associated with palliative care of specific PBT types or grades. When data for all PBT is pooled, the median survival time (MST) following palliative care is $\sim 9$ weeks, with a range of 1-13 weeks $(3,13,21,154,157-159)$. However, published data does indicate that some dogs with rostrotentorial tumors can experience survivals in excess of 6 months with palliative management (21).

\section{Chemotherapy}

Data evaluating the efficacy of systemically administered chemotherapies for the management of brain tumors in dogs is significantly limited by the lack of definitive tumor diagnoses in the vast majority of reported cases, variable dosing regimens, and a preponderance of small case series examining specific drugs $(158,159)$. The most commonly used chemotherapeutics for brain tumors are the alkylating agents lomustine $(\mathrm{CCNU})$, carmustine $(\mathrm{BCNU})$ and temozolomide (TMZ), or the antimetabolite hydroxyurea, all of which penetrate the blood-brain-barrier (BBB) (158-160). One retrospective study in 71 dogs with presumptively diagnosed brain tumors reported that lomustine treated dogs ( $n=56$, MST 3 months) experienced no survival benefit compared to dogs receiving palliative therapy ( $n=15$, MST 2 months) (158). In another study conducted in dogs with intra-axial mass lesions (presumptively diagnosed gliomas), dogs treated with lomustine ( $n=17$, MST 4.5 months) survived significantly longer than dogs receiving palliative care only ( $n=23$; MST 1 month) (159). In general, the prognosis is poor for dogs with PBT treated with chemotherapy when used as a monotherapy in the setting of gross disease. No difference in survival was also reported between groups of dogs with presumptively diagnosed gliomas treated with stereotactic radiotherapy with ( $n=20$, MST 13.5 months) or without ( $n=$ 22, MST 12.4 months) TMZ (160).

At the dose intensities reported in the literature, toxicities associated with CCNU, TMZ and hydroxyurea occur commonly but are rarely life-threatening or require discontinuation of therapy in dogs with brain tumors (158-160).

There is mechanistic justification for the investigation of the utility of existing and new classes of drugs for targeted use in canine brain tumors. Non-steroidal antiinflammatory drugs (NSAIDs), particularly COX-2 selective inhibitors, have numerous potential, but largely unexplored uses for the management of brain tumors. In addition to their use for analgesia, NSAIDs can have antitumor, antiedema, and immunomodulatory effects in humans and dogs (161, 162). Overexpression of COX-2 has been demonstrated in canine meningiomas, and this overexpression can promote cancer cell proliferation, angiogenesis, and peritumoral edema, reduce apoptosis of neoplastic cells, and decrease antitumor immunity (161-163). As VEGF/VEGFR1/2 and PDGFRa are also overexpressed in a variety of canine PBT, administration of VEGF-targeted antiangiogenic agents, such as bevacizumab, or the receptor tyrosine kinase inhibitors masitinib or toceranib phosphate have potential for therapeutic use in brain tumors $(60,86,133,134,164)$. 
In vitro investigations have demonstrated that responses to chemotherapeutic agents such as bleomycin, carboplatin, CCNU, irinotecan, and TMZ, as well as mechanisms of chemoresistance observed in canine glioma cell lines parallel those seen in human glioma cell lines $(93,165)$. Thus, it is reasonable to expect that the inclusion of adjuvant chemotherapy in multimodality canine brain tumor treatment protocols could result in modest clinical benefits, as is generally seen in humans. Metronomic chemotherapy with chlorambucil in conjunction with surgical resection is currently being evaluated in an early phase trial in dogs with gliomas (166). The histopathologic and molecular characterization of canine brain tumors and creation of additional of canine patient-derived tumor cell lines will be paramount to efforts necessary to develop and evaluate brain tumor-specific drug protocols, such as high-throughput drug library screening and the identification of biomarkers that predict chemoresponsiveness.

\section{Surgery}

Benefits associated with surgical resection of brain tumors include the rapid reduction or elimination of the tumor burden, the secondary beneficial effect this has on reducing ICP, and allowing for definitive histopathological diagnosis of the tumor. Numerous variables complicate critical comparisons of studies evaluating the efficacy surgical treatment of specific tumor types including the experience of the surgeon, availability, or standardized protocols for usage of a growing number of operating room technologies that may facilitate resection, and a nearly universal lack of inclusion of quantifiable surrogates of surgical success, such as surgeon- or imaging-based extent of resection (EOR) assessments $(167,168)$. Given that attainment of wide excisions of brain tumors are generally not possible for margin evaluation, objective evaluation of EOR is currently dependent on MRI-based assessments, which are associated with practical limitations including the need for anesthesia, expense and difficulties distinguishing residual tumor from surgically induced reactive changes in the acute postoperative period (167, 169).

Outcomes associated with surgical management of canine meningiomas are highly variable, reflective of the previously identified operator and technical factors, in addition to the propensity for all grades of canine meningiomas to locally invade brain tissue (7). Most surgical studies of canine meningiomas have included predominantly superficially located rostrotentorial tumors (170-174). Surgical treatment of basilar, cerebellopontomedulary angle, foramen magnum, parasellar, and tentorial meningiomas is technically challenging and has not been frequently reported (173). When standard cytoreductive surgical techniques are used, the average MST for canine meningiomas is $\sim 10$ months $(170-172,174,175)$. Studies describing the use of techniques or technologies that facilitate removal of infiltrative tumor or intraoperative visualization such as cortical resection, usage of an ultrasonic aspirator, or endoscopic assisted resection in canine meningiomas report superior MST (16-70 months) compared to conventional surgical methods $(172,173,176)$. Dogs with meningiomas treated surgically also benefit from the addition of adjunctive radiation therapy (RT), as MST associated with multimodal surgery and RT protocols range from 16 and 30 months $(130,171,177)$.

There is relatively little data regarding the surgical treatment of other PBT such gliomas and choroid plexus tumors, although a few individual animals with these tumor types experienced prolonged survivals after surgery (8, 152, 157, 178, 179). Surgical treatment of these tumors is infrequently attempted as approaching and removing them is technically demanding due to their intra-axial or intraventricular locations. In addition, as these tumors are poorly delineated and locally invasive, it is inherently more difficult to discriminate the margins of tumor from the neighboring neural tissue. Outcomes in the current literature suggests that surgery should probably not be used as a sole treatment modality for canine gliomas, as MST for rostrotentorial gliomas treated surgically was 2 months (174). MST of $\sim 6$ months have been reported in dogs with gliomas treated surgically in combination with metronomic chemotherapy or immunotherapy $(166,180)$. Resection of these tumors types is likely to become more common and efficacious with the evolution of brain imaging techniques, intraoperative stereotactic and neuronavigational systems, minimally invasive automated tissue resection devices, and "tumor painting" with fluorophores to assist with intraoperative visualization of tumors (152, 153, 181, 182).

The frequency of significant adverse events associated with surgical treatment of PBT varies widely between individual studies, ranging from 6 and 100\% (157, 166, 170$176,178,179,183)$. Removing the outlier study with $100 \%$ perioperative mortality results in an average rate of acute perioperative mortality of $\sim 11 \%$, although nearly $50 \%$ of dogs experience acute adverse effects associated with intracranial surgery in studies that focus on adverse event reporting $(154,179,183)$. Common causes of morbidity and early perioperative mortality include aspiration pneumonia, intracranial hemorrhage or infarction, pneumocephalus, medically refractory provoked seizures, transient or permanent neurological disability, electrolyte and osmotic disturbances, and thermoregulatory dysfunction $(154,183)$.

\section{Radiation Therapy (RT)}

$\mathrm{RT}$ is beneficial for the treatment of PBT when used as a monotherapy or adjunctive modality. Extrapolating meaningful outcome data from the veterinary brain tumor RT literature associated with specific tumor types in confounded by a general lack of histologically diagnosed tumors included in RT studies, grouping of highly heterogeneous intracranial masses, which sometimes include PBT and SBT in data analyses, and considerable variability in the RT types and dose prescriptions used. RT equipment and techniques have advanced from the early use of orthovoltage RT to current predominantly linear accelerator based options, including advanced forms of intensitymodulated RT (IMRT) such as VMAT and tomotherapy, as well as stereotactic RT (SRT) and stereotactic radiosurgery (SRS) $(160,184)$.

Cohorts of dogs treated with RT as a sole treatment modality for presumptively diagnosed brain tumors indicate an average survival of $\sim 16$ months, with reported overall MST ranging 
from 7 and 24 months when all treated intracranial masses are analyzed (157, 160, 171, 177, 184-191). Some RT studies reported that extra-axial tumors (meningiomas) have a more favorable prognosis than intra-axial (glial) tumors (157, 187, 191). MST associated with RT treatment of extra-axial masses, the majority of which were presumptively diagnosed meningiomas, range from 9 and 30 months, and MST reported for intra-axial masses range from 7.5 and 13 months $(33,157,160,171,177,184,186-$ 191). Given the variable outcomes associated with both RT and surgery, there is currently no clearly superior choice between these two modalities when either is used a sole treatment for canine meningiomas (154).

RT also has utility in the adjunctive therapy of canine meningiomas, with combined surgical and RT therapy producing MST of 16-30 months (130, 171, 177). A select number of molecular biomarkers have been evaluated for their prognostic value in dogs with meningiomas treated with surgery and RT. In one study of 17 dogs treated with surgery and adjunctive hypofractionated RT, survival was negatively correlated with VEGF expression (132). The MST was 25 months for dogs with tumors with $\leq 75 \%$ cells demonstrating immunoreactivity to VEGF compared with 15 months for dogs with tumors with $>75 \%$ of cell staining for VEGF, and dogs with tumors demonstrating more intense VEGF immunoreactivity also had a significantly shorter survival time (132). In a study that included 70 dogs with meningiomas treated with surgery and hypofractionated RT, tumor proliferative indices were assessed via MIB-1/Ki67 IHC, and were not associated with survival (134). There was also no association between VEGF and MIB-1/Ki67 expression (134). Progesterone receptor expression has also been shown to be inversely related to the tumor proliferative index ( PFCNA $_{\text {PCN }}$ inex, which was predictive of survival in dogs with meningiomas after surgery and postoperative RT. The 2-year progression-free survival was $42 \%$ for tumors with a PFPCNA index $\geq 24$ and $91 \%$ for tumors with a PFPCNA index $<24 \%$ (130).

Approximately $10 \%$ of brain tumor cases treated with RT will experience treatment-related mortality or adverse effects (154). Frequently reported adverse effects include aspiration pneumonia, pulmonary thromboembolism, acute CNS toxicity which often manifests as a decreased level of consciousness, damage to at risk organs in the treatment field including deafness, cataract formation, and keratitis, and late-onset radiation necrosis (154). Although significant adverse events associated with SRT and SRS have been uncommonly reported in animals to date, the more frequent use of high-dose per fraction prescriptions may eventually influence the incidence of observed toxicity.

\section{NOVEL THERAPEUTIC APPROACHES}

The potential of pet dog dogs with naturally occurring cancers to provide answers to fundamental cancer drug and device development questions that meet a critical and shared need among stakeholders in the cancer research and global healthcare communities is being increasingly realized $(192,193)$. Translational studies in brain tumor-bearing dogs can provide a variety of safety, pharmacokinetic, mechanistic, toxicity and antitumor activity data in an immunocompetent host, and thus offer numerous opportunities to guide the therapeutic development process. The current landscape of comparative veterinary neurooncologic research encompasses four primary focus areas: (1) novel, macroscopic tumor targeting, imaging, or CNS delivery techniques, (2) therapeutics molecularly targeting tumor-specific markers or aberrant cellular pathways, (3) immunotherapy, and (4) modifications of the dosing or chemistry of existing or repurposing of therapeutics based on new mechanistic discoveries. Several of these therapeutic approaches have been evaluated in early phase clinical trials in dogs with brain tumors, and numerous others are in the pre-clinical developmental stages.

Macroscopic tumor targeting techniques seek to eliminate of the tumor burden by facilitating gross surgical resection or delivery of ablative energy doses by improving visualization of or sensitizing cancerous tissue, or to overcome therapeutic the drug delivery limitations imposed by the BBB in brain tissue within and surrounding the tumor mass that is visible on imaging studies. The use of intraoperative stereotactic equipment and neuronavigational systems with various tissue resection devices and techniques are being actively investigated for the surgical biopsy and treatment of canine brain tumors $(152,154,181)$. The safety and feasibility of stereotactic tumor ablation using lasers and pulsed electrical fields have also been demonstrated in canine brain tumors (194-196). BBB disruptive technologies that allow for CNS drug delivery such as transcranial focused ultrasound and irreversible electroporation are also being used to treat canine brain tumors $(195,197)$. Convection-enhanced delivery (CED), an approach that bypasses the BBB and allows for direct intratumoral delivery of macromolecular drugs, has been used to evaluate the toxicity and preliminary efficacy of a variety of non-selective and targeted chemotherapeutics, gene therapy, and biodegradable nanomaterial drug carriers in several early phase trials in dogs with brain tumors (152, 153, 197-202). In dogs with intracranial gliomas, studies investigating intratumoral CED of non-selective chemotherapeutics, such as irinotecan (198), and molecularly targeted agents, including EGFRvIII- antibody conjugated magnetic iron oxide nanoparticles (201) and modified bacterial cytotoxins conjugated to IL-13RA2 and EphA2 receptor ligands (197), all have been shown to be capable of inducing significant antitumor effects without major adverse effects.

There is an expanding library of targeted agents being developed for and tested in canine brain tumors, and these agents represent a wide variety of mechanistic approaches including protease-conjugated oncolytic viruses, immunomodulatory microRNAs or small interfering RNAs, immune-checkpoint inhibitors, apoptosis promoters, radiosensitizing agents, and nanoparticular cytotoxic drugs. These compounds have shown promising anti-tumor effects in vitro or in vivo against non-CNS tumors, the ability to penetrate the $\mathrm{BBB}$ when administered systemically, or favorable safety and pharmacokinetic profiles in healthy dogs, and are currently in early phase trials in dogs with tumors (197, 203-206). Proof-of principle studies have demonstrated that both EGFR targeted, doxorubicin loaded minicells (204) and PAC-1, a pro-apoptotic, BBBpenetrant small molecule activator of procaspase-3 are capable of 
achieving clinically relevant intratumoral concentrations when administered systemically to dogs with naturally brain tumors (205). The promising pre-clinical safety, pharmacokinetic, and antitumor results from the canine EGFR targeted, doxorubicin minicells study subsequently informed the design of a Phase I clinical trial applying this approach in human recurrent glioblastoma patients (204).

Numerous immunotherapy strategies whose unifying goal is to augment the patient's T-cell mediated immune response against cancer cells are being explored for use in companion animal brain tumors $(152,153)$. IT approaches that involve tumor vaccinations with stimulated patient-derived dendritic cells and autologous tumor lysates combined with toll-like receptor ligand adjuvants or immune-checkpoint inhibitors have demonstrated the safety, feasibility and potential efficacy of IT for use in canine glioma and meningioma (175, 207-209). In dogs with meningiomas, vaccination with an autologous tumor cell lysate combined with synthetic toll-like receptor ligands after cytoreductive surgery increased survival (median 645 days) compared with surgically treated historic controls (median 222 days), and the vaccine was demonstrated to induce tumor reactive antibodies (175). Extending findings observed in rodent models which demonstrated that administration of a CD200 peptide inhibitor overcomes immune tolerance induced by tumor vaccination by increasing leukocyte infiltration into the vaccine site, bolstering cytokine and chemokine production, and enhancing tumor cytolytic activity, this approach was recently evaluted in dogs with high-grade gliomas (209). In this study, gliomas were treated with cytoreductive surgery followed by intradermal injection of a CD200-directed peptide prior to delivery of an autologous tumor lysate vaccine. Dogs receiving the canine-specific CD200-directed inhibitor and the autologous tumor lysate had significanlty longer survivals (median 12.7 months) compared to a historical control group of dogs treated with surgery and autologous tumor lysate (median 6.4 months).

There are currently two studies that have evaluated modified dosing regimens of existing chemotherapeutics or repurposing of drugs specifically using canine models of brain cancer. One in vivo study demonstrated that metronomic

\section{REFERENCES}

1. Priester WA, Mantel N. Occurrence of tumors in domestic animals. Data from 12 United States and Canadian colleges of veterinary medicine. J Natl Cancer Inst. (1971) 47:1333-44.

2. Hayes HM, Priester WA Jr, Pendergrass TW. Occurrence of nervous-tissue tumors in cattle, horses, cats and dogs. Int J Cancer. (1975) 15:39-47. doi: 10.1002/ijc.2910150106

3. Snyder JM, Shofer FS, Van Winkle TJ, Massicotte C. Canine intracranial primary neoplasia: 173 cases (1986-2003). J Vet Intern Med. (2006) 20:66975. doi: 10.1111/j.1939-1676.2006.tb02913.x

4. Song RB, Vite CH, Bradley CW, Cross JR. Postmortem evaluation of 435 cases of intracranial neoplasia in dogs and relationship of neoplasm with breed, age, and body weight. J Vet Intern Med. (2013) 27:1143-52. doi: 10.1111 /jvim. 12136

5. Dorn CR, Taylor DO, Frye FL, Hibbard HH. Survey of animal neoplasms in Alameda and Contra Costa Counties, California. I Methodology and description of cases. J Natl Cancer Inst. (1968) 40:295-305. chemotherapy with chlorambucil and lomustine in combination of surgical resection of canine gliomas was well tolerated and capable of achieving potentially therapeutic intratumoral drug concentrations (166). An additional in vitro study using canine glioma cell lines reported that benzimidazole anthelmintic treatment increased depolymerization of tubulin and glioma cell cytotoxicity compared to the controls (210), suggesting that both mebendazole and fenbendazole may be reasonable drug candidates for the treatment of canine glioma especially given their established safety profiles.

Advancements in the fields of veterinary and comparative neurooncology will require a change in current daily practice paradigms in which the biopsy of individual animal tumors prior to treatment becomes the new standard of care. This will facilitate the routine and systematic characterization of the histomorphologic and molecular features of canine brain cancers, the continuing global comparative genomic analyses of human and veterinary nervous system neoplasms, and the hosting of comprehensively annotated clinicopathological and neuroradiological data registries. These needs have been further recognized by the neurooncology community, and have begun to be addressed by several projects being conducted by the NCI Comparative Brain Tumor Consortium (193, 211). The NCI Comparative Brain Tumor Consortium was the driving force behind the categorization of canine glioma and has recently embarked on a similar goal of redefining the pathologic features of canine meningioma (78). These coordinated efforts are crucial to determining any prognostic relevance of tumor grading, objectively defining the impacts of treatment modalities on clinical outcomes associated with specific tumors, and the rigorous design of clinical trials, especially considering the expanding repertoire of targeted agents available for cancer diagnostics and treatment.

\section{AUTHOR CONTRIBUTIONS}

All authors listed have made a substantial, direct and intellectual contribution to the work, and approved it for publication.
6. Snyder JM, Lipitz L, Skorupski KA, Shofer FS, Van Winkle TJ. Secondary intracranial neoplasia in the dog: 177 cases (1986-2003). J Vet Intern Med. (2008) 22:172-7. doi: 10.1111/j.1939-1676.2007.0002.x

7. Sturges BK, Dickinson PJ, Bollen AW, Koblik PD, Kass PH, Kortz $\mathrm{GD}$, et al. Magnetic resonance imaging and histological classification of intracranial meningiomas in 112 dogs. J Vet Intern Med. (2008) 22:586-95. doi: $10.1111 / j .1939-1676.2008 .00042 . x$

8. Westworth DR, Dickinson PJ, Vernau W, Johnson EG, Bollen AW, Kass PH, et al. Choroid plexus tumors in 56 dogs (1985-2007). J Vet Intern Med. (2008) 22:1157-65. doi: 10.1111/j.1939-1676.2008.0170.x

9. Kube SA, Bruyette DS, Hanson SM. Astrocytomas in young dogs. J Am Anim Hosp Assoc. (2003) 39:288-93. doi: 10.5326/0390288

10. Truve K, Dickinson P, Xiong A, York D, Jayashankar K, Pielberg G, et al. Utilizing the dog genome in the search for novel candidate genes involved in glioma development-genome wide association mapping followed by targeted massive parallel sequencing identifies a strongly associated locus. PLoS Genet. (2016) 12:e1006000. doi: 10.1371/journal.pgen.10 06000 
11. Rossmeisl JH, Pancotto TE. Intracranial neoplasia and secondary pathological effects. In: Platt S, Garosi L, editors. Small Animal Neurological Emergencies. London: Manson Publishing Ltd. (2012). p. 461-78. doi: 10.1201/b15214-30

12. Palmer AC, Malinowski W, Barnett KC. Clinical signs including papilloedema associated with brain tumours in twenty-one dogs. J Small Anim Pract. (1974) 15:359-86. doi: 10.1111/j.1748-5827.1974.tb06512.x

13. Foster ES, Carrillo JM, Patnaik AK. Clinical signs of tumors affecting the rostral cerebrum in 43 dogs. J Vet Intern Med. (1988) 2:71-4. doi: 10.1111/j.1939-1676.1988.tb02796.x

14. Bagley RS, Gavin PR. Seizures as a complication of brain tumors in dogs. Clin Tech Small Anim Pract. (1998) 13:179-84. doi: 10.1016/S1096-2867(98)80039-X

15. Bagley RS, Gavin PR, Moore MP, Silver GM, Harrington ML, Connors RL. Clinical signs associated with brain tumors in dogs: 97 cases (1992-1997). J Am Vet Med Assoc. (1999) 215:818-9.

16. Schwartz M, Lamb CR, Brodbelt DC, Volk HA. Canine intracranial neoplasia: clinical risk factors for development of epileptic seizures. J Small Anim Pract. (2011) 52:632-7. doi: 10.1111/j.1748-5827.2011.01131.x

17. Menchetti M, De Risio L, Galli G, Bruto Cherubini G, Corlazzoli D, Baroni $\mathrm{M}$, et al. Neurological abnormalities in 97 dogs with detectable pituitary masses. Vet Q. (2019) 39:57-64. doi: 10.1080/01652176.2019.1622819

18. Beaumont A, Whittle IR. The pathogenesis of tumour associated epilepsy. Acta Neurochir. (2000) 142:1-15. doi: 10.1007/s007010050001

19. Aronica E, Gorter JA, Jansen GH, Leenstra S, Yankaya B, Troost D. Expression of connexin 43 and connexin 32 gap-junction proteins in epilepsy-associated brain tumors and in the perilesional epileptic cortex. Acta Neuropathol. (2001) 101:449-59. doi: 10.1007/s004010000305

20. Bartolomei F, Bosma I, Klein M, Baayen JC, Reijneveld JC, Postma $\mathrm{TJ}$, et al. How do brain tumors alter functional connectivity? A magnetoencephalography study. Ann Neurol. (2006) 59:128-38. doi: 10.1002/ana.20710

21. Rossmeisl JHJr, Jones JC, Zimmerman KL, Robertson JL. Survival time following hospital discharge in dogs with palliatively treated primary brain tumors. J Am Vet Med Assoc. (2013) 242:193-8. doi: 10.2460/javma.242.2.193

22. Wood FD, Pollard RE, Uerling MR, Feldman EC. Diagnostic imaging findings and endocrine test results in dogs with pituitary-dependent hyperadrenocorticism that did or did not have neurologic abnormalities: 157 cases (1989-2005). J Am Vet Med Assoc. (2007) 231:1081-5. doi: 10.2460/javma.231.7.1081

23. Koch MW, Sanchez MD, Long S. Multifocal oligodendroglioma in three dogs. J Am Anim Hosp Assoc. (2011) 47:e77-85. doi: 10.5326/JAAHA-MS-5551

24. Bentley RT, Burcham GN, Heng HG, Levine JM, Longshore R, CarreraJustiz S, et al. A comparison of clinical, magnetic resonance imaging and pathological findings in dogs with gliomatosis cerebri, focusing on cases with minimal magnetic resonance imaging changes(double dagger). Vet Comp Oncol. (2016) 14:318-30. doi: 10.1111/vco.12106

25. Rossmeisl JH, Clapp K, Pancotto TE, Emch S, Robertson JL, Debinski W. Canine butterfly glioblastomas: a neuroradiological review. Front Vet Sci. (2016) 3:40. doi: 10.3389/fvets.2016.00040

26. Lobacz MA, Serra F, Hammond G, Oevermann A, Haley AC. Imaging diagnosis-magnetic resonance imaging of diffuse leptomeningeal oligodendrogliomatosis in a dog with "Dural Tail Sign". Vet Radiol Ultrasound. (2018) 59:E1-E6. doi: 10.1111/vru.12441

27. Mcdonnell JJ, Kalbko K, Keating JH, Sato AF, Faissler D. Multiple meningiomas in three dogs. J Am Anim Hosp Assoc. (2007) 43:201-8. doi: $10.5326 / 0430201$

28. Stacy BA, Stevenson TL, Lipsitz D, Higgins RJ. Simultaneously occurring oligodendroglioma and meningioma in a dog. J Vet Intern Med. (2003) 17:357-9. doi: 10.1111/j.1939-1676.2003.tb02462.x

29. Alves A, Prada J, Almeida JM, Pires I, Queiroga F, Platt SR, et al. Primary and secondary tumours occurring simultaneously in the brain of a dog. J Small Anim Pract. (2006) 47:607-10. doi: 10.1111/j.1748-5827.2006.00066.x

30. Patnaik AK, Erlandson RA, Lieberman PH, Fenner WR, Prata RG. Choroid plexus carcinoma with meningeal carcinomatosis in a dog. Vet Pathol. (1980) 17:381-5. doi: $10.1177 / 030098588001700312$
31. Bigio Marcello A, Gieger TL, Jimenez DA, Granger LA. Detection of comorbidities and synchronous primary tumours via thoracic radiography and abdominal ultrasonography and their influence on treatment outcome in dogs with soft tissue sarcomas, primary brain tumours and intranasal tumours. Vet Comp Oncol. (2015) 13:433-42. doi: 10.1111/vco.12063

32. Tong NM, Zwingenberger AL, Blair WH, Taylor SL, Chen RX, Sturges BK. Effect of screening abdominal ultrasound examination on the decision to pursue advanced diagnostic tests and treatment in dogs with neurologic disease. J Vet Intern Med. (2015) 29:893-9. doi: 10.1111/jvim.12602

33. Turrel JM, Fike JR, Lecouteur RA, Higgins RJ. Computed tomographic characteristics of primary brain tumors in 50 dogs. J Am Vet Med Assoc. (1986) 188:851-6.

34. Shores A, Warber-Matich S, Cooper TG. The role of magnetic resonance spectroscopy in neuro-oncology. Semin Vet Med Surg. (1990) 5:237-40.

35. Wolf M, PedroiaV, Higgins RJ, Koblik PD, Turrel JM, Owens JM. Intracranial ring enhancing lesions in dogs: a correlative CT scanning and neuropathologic study. Vet Radiol Ultrasound. (1995) 36:16-20. doi: 10.1111/j.1740-8261.1995.tb00206.x

36. Hathcock J. Low field magnetic resonace imaging characteristics of cranial vault meningiomas in 13 dogs. Vet Radiol Ultrasound. (1996) 37:257-63. doi: 10.1111/j.1740-8261.1996.tb01227.x

37. Thomas WB, Wheeler SJ, Kramer R, Kornegay JN. Magnetic resonace imaging features of primary brain tumors in dogs. Vet Radiol Ultrasound. (1996) 37:20-7. doi: 10.1111/j.1740-8261.1996.tb00807.x

38. Graham JP, Newell SM, Voges AK, Roberts GD, Harrison JM. The dural tail sign in the diagnosis of meningiomas. Vet Radiol Ultrasound. (1998) 39:297-302. doi: 10.1111/j.1740-8261.1998.tb01609.x

39. Polizopoulou ZS, Koutinas AF, Souftas VD, Kaldrymidou E, Kazakos G, Papadopoulos G. Diagnostic correlation of CT-MRI and histopathology in 10 dogs with brain neoplasms. J Vet Med A Physiol Pathol Clin Med. (2004) 51:226-31. doi: 10.1111/j.1439-0442.2004.00633.x

40. Cherubini GB, Mantis P, Martinez TA, Lamb CR, Cappello R. Utility of magnetic resonance imaging for distinguishing neoplastic from nonneoplastic brain lesions in dogs and cats. Vet Radiol Ultrasound. (2005) 46:384-7. doi: 10.1111/j.1740-8261.2005.00069.x

41. Macleod AG, Dickinson PJ, Lecouteur RA, Higgins RJ, Pollard RE. Quantitative assessment of blood volume and permeability in cerebral mass lesions using dynamic contrast-enhanced computed tomography in the dog. Acad Radiol. (2009) 16:1187-95. doi: 10.1016/j.acra.2009.03.015

42. Zhao Q, Lee S, Kent M, Schatzberg S, Platt S. Dynamic contrast-enhanced magnetic resonance imaging of canine brain tumors. Vet Radiol Ultrasound. (2010) 51:122-9. doi: 10.1111/j.1740-8261.2009.01635.x

43. Cervera V, Mai W, Vite CH, Johnson V, Dayrell-Hart B, Seiler GS. Comparative magnetic resonance imaging findings between gliomas and presumed cerebrovascular accidents in dogs. Vet Radiol Ultrasound. (2011) 52:33-40. doi: 10.1111/j.1740-8261.2010.01749.x

44. Rodenas S, Pumarola M, Gaitero L, Zamora A, Anor S. Magnetic resonance imaging findings in 40 dogs with histologically confirmed intracranial tumours. Vet J. (2011) 187:85-91. doi: 10.1016/j.tvjl.2009.10.011

45. Sutherland-Smith J, King R, Faissler D, Ruthazer R, Sato A. Magnetic resonance imaging apparent diffusion coefficients for histologically confirmed intracranial lesions in dogs. Vet Radiol Ultrasound. (2011) 52:142-8. doi: 10.1111/j.1740-8261.2010.01764.x

46. Wisner ER, Dickinson PJ, Higgins RJ. Magnetic resonance imaging features of canine intracranial neoplasia. Vet Radiol Ultrasound. (2011) 52:S52-61. doi: $10.1111 / j .1740-8261.2010 .01785 . x$

47. Young BD, Levine JM, Porter BF, Chen-Allen AV, Rossmeisl JH, Platt SR, et al. Magnetic resonance imaging features of intracranial astrocytomas and oligodendrogliomas in dogs. Vet Radiol Ultrasound. (2011) 52:132-41. doi: $10.1111 / j .1740-8261.2010 .01758 . x$

48. Martin-Vaquero P, Da Costa RC, Echandi RL, Sammet CL, Knopp MV, Sammet S. Magnetic resonance spectroscopy of the canine brain at $3.0 \mathrm{~T}$ and 7.0 T. Res Vet Sci. (2012) 93:427-9. doi: 10.1016/j.rvsc.2011.07.025

49. Wolff CA, Holmes SP, Young BD, Chen AV, Kent M, Platt SR, et al. Magnetic resonance imaging for the differentiation of neoplastic, inflammatory, and cerebrovascular brain disease in dogs. J Vet Intern Med. (2012) 26:589-97. doi: 10.1111/j.1939-1676.2012.00899.x 
50. Bentley RT, Ober CP, Anderson KL, Feeney DA, Naughton JF, Ohlfest JR, et al. Canine intracranial gliomas: relationship between magnetic resonance imaging criteria and tumor type and grade. Vet J. (2013) 198:463-71. doi: 10.1016/j.tvjl.2013.08.015

51. Bentley RT. Magnetic resonance imaging diagnosis of brain tumors in dogs. Vet J. (2015) 205:204-16. doi: 10.1016/j.tvjl.2015.01.025

52. Banzato T, Bernardini M, Cherubini GB, Zotti A. Texture analysis of magnetic resonance images to predict histologic grade of meningiomas in dogs. Am J Vet Res. (2017) 78:1156-62. doi: 10.2460/ajvr.78.10.1156

53. Stadler KL, Pease AP, Ballegeer EA. Dynamic susceptibility contrast magnetic resonance imaging protocol of the normal canine brain. Front Vet Sci. (2017) 4:41. doi: 10.3389/fvets.2017.00041

54. Bailey CS, Higgins RJ. Characteristics of cisternal cerebrospinal fluid associated with primary brain tumors in the dog: a retrospective study. J Am Vet Med Assoc. (1986) 188:414-7.

55. Dickinson PJ, Sturges BK, Kass PH, Lecouteur RA. Characteristics of cisternal cerebrospinal fluid associated with intracranial meningiomas in dogs: 56 cases (1985-2004). J Am Vet Med Assoc. (2006) 228:564-7. doi: 10.2460/javma.228.4.564

56. Bohn AA, Wills TB, West CL, Tucker RL, Bagley RS. Cerebrospinal fluid analysis and magnetic resonance imaging in the diagnosis of neurologic disease in dogs: a retrospective study. Vet Clin Pathol. (2006) 35:315-20. doi: 10.1111/j.1939-165X.2006.tb00138.x

57. Tzipory L, Vernau KM, Sturges BK, Zabka TS, Highland MA, Petersen $\mathrm{SA}$, et al. Antemortem diagnosis of localized central nervous system histiocytic sarcoma in 2 dogs. J Vet Intern Med. (2009) 23:369-74. doi: 10.1111/j.1939-1676.2008.0264.x

58. Palus V, Volk HA, Lamb CR, Targett MP, Cherubini GB. MRI features of CNS lymphoma in dogs and cats. Vet Radiol Ultrasound. (2012) 53:44-9. doi: $10.1111 /$ j.1740-8261.2011.01872.x

59. Platt SR, Marlin D, Smith N, Adams V. Increased cerebrospinal fluid uric acid concentrations in dogs with intracranial meningioma. Vet Rec. (2006) 158:830. doi: 10.1136/vr.158.24.830

60. Rossmeisl JH, Duncan RB, Huckle WR, Troy GC. Expression of vascular endothelial growth factor in tumors and plasma from dogs with primary intracranial neoplasms. Am J Vet Res. (2007) 68:1239-45. doi: 10.2460/ajvr.68.11.1239

61. Turba ME, Forni M, Gandini G, Gentilini F. Recruited leukocytes and local synthesis account for increased matrix metalloproteinase- 9 activity in cerebrospinal fluid of dogs with central nervous system neoplasm. $J$ Neurooncol. (2007) 81:123-9. doi: 10.1007/s11060-006-9213-2

62. De La Fuente C, Monreal L, Ceron J, Pastor J, Viu J, Anor S. Fibrinolytic activity in cerebrospinal fluid of dogs with different neurological disorders. $J$ Vet Intern Med. (2012) 26:1365-73. doi: 10.1111/j.1939-1676.2012.00991.x

63. Mariani CL, Boozer LB, Braxton AM, Platt SR, Vernau KM, Mcdonnell JJ, et al. Evaluation of matrix metalloproteinase-2 and -9 in the cerebrospinal fluid of dogs with intracranial tumors. Am J Vet Res. (2013) 74:122-9. doi: 10.2460/ajvr.74.1.122

64. Miyake H, Inoue A, Tanaka M, Matsuki N. Serum glial fibrillary acidic protein as a specific marker for necrotizing meningoencephalitis in Pug dogs. J Vet Med Sci. (2013) 75:1543-5. doi: 10.1292/jvms.13-0252

65. Utsugi S, Azuma K, Osaki T, Murahata Y, Tsuka T, Ito N, et al. Analysis of plasma free amino acid profiles in canine brain tumors. Biomed Rep. (2017) 6:195-200. doi: 10.3892/br.2016.825

66. Li C-F, Mellema M, Carney R, Sturges B, York D, Liu R, et al. Exosomeassociated integrins as liquid biopsy biomarkers for canine glioma. $J$ Vet Intern Med. (2017) 31:1261.

67. Lake BB, Rossmeisl JH, Cecere J, Stafford P, Zimmerman KL. Immunosignature differentiation of non-infectious meningoencephalomyelitis and intracranial neoplasia in dogs. Front Vet Sci. (2018) 5:97. doi: 10.3389/fvets.2018.00097

68. Harari JM, Leathers MM, Roberts CW, Gavin PR. Computed tomographicguided, free-hand needle biopsy of brain tumors in dogs. Prog Vet Neurol. (1993) 4:41-44.

69. Koblik PD, Lecouteur RA, Higgins RJ, Bollen AW, Vernau KM, Kortz GD, et al. CT-guided brain biopsy using a modified Pelorus Mark III stereotactic system: experience with 50 dogs. Vet Radiol Ultrasound. (1999) 40:434-40. doi: 10.1111/j.1740-8261.1999.tb00371.x
70. Moissonnier P, Blot S, Devauchelle P, Delisle F, Beuvon F, Boulha L, et al. Stereotactic CT-guided brain biopsy in the dog. J Small Anim Pract. (2002) 43:115-23. doi: 10.1111/j.1748-5827.2002.tb00041.x

71. Klopp LS, Ridgway M. Use of an endoscope in minimally invasive lesion biopsy and removal within the skull and cranial vault in two dogs and one cat. J Am Vet Med Assoc. (2009) 234:1573-7. doi: 10.2460/javma.234.12.1573

72. Rossmeisl JH, Andriani RT, Cecere TE, Lahmers K, Leroith T, Zimmerman $\mathrm{KL}$, et al. Frame-based stereotactic biopsy of canine brain masses: technique and clinical results in 26 cases. Front Vet Sci. (2015) 2:20. doi: $10.3389 /$ fvets. 2015.00020

73. Sidhu DS, Ruth JD, Lambert G, Rossmeisl JH. An easy to produce and economical three-dimensional brain phantom for stereotactic computed tomographic-guided brain biopsy training in the dog. Vet Surg. (2017) 46:621-30. doi: 10.1111/vsu.12657

74. Kani Y, Cecere TE, Lahmers K, Leroith T, Zimmerman KL, Isom S, et al. Diagnostic accuracy of stereotactic brain biopsy for intracranial neoplasia in dogs: comparison of biopsy, surgical resection, and necropsy specimens. $J$ Vet Intern Med. (2019) 33:1384-91. doi: 10.1111/jvim.15500

75. Stadler KL, Ruth JD, Pancotto TE, Werre SR, Rossmeisl JH. Computed tomography and magnetic resonance imaging are equivalent in mensuration and similarly inaccurate in grade and type predictability of canine intracranial gliomas. Front Vet Sci. (2017) 4:157. doi: 10.3389/fvets.2017.00157

76. Stadler KL, Ober CP, Feeney DA, Jessen CR. Multivoxel proton magnetic resonance spectroscopy of inflammatory and neoplastic lesions of the canine brain at 3.0 T. Am J Vet Res. (2014) 75:982-9. doi: 10.2460/ajvr.75.11.982

77. Rissi DR, Levine JM, Eden KB, Watson VE, Griffin JFT, Edwards JF, et al. Cerebral oligodendroglioma mimicking intraventricular neoplasia in three dogs. J Vet Diagn Invest. (2015) 27:396-400. doi: 10.1177/1040638715584619

78. Koehler JW, Miller AD, Miller CR, Porter B, Aldape K, Beck J, et al. A revised diagnostic classification of canine glioma: towards validation of the canine glioma patient as a naturally occurring preclinical model for human glioma. J Neuropathol Exp Neurol. (2018) 77:1039-54. doi: 10.1093/jnen/nly085

79. Nakamoto Y, Fukunaga D, Uchida K, Mori T, Kishimoto T, Ozawa T. Anaplastic oligodendroglioma with leptomeningeal dissemination in a french bulldog. J Vet Med Sci. (2018) 80:1590-5. doi: 10.1292/jvms.17-0652

80. Recio A, De La Fuente C, Pumarola M, Espada Y, Anor S. Magnetic resonance imaging and computed tomographic characteristics of a glioma causing calvarial erosion in a dog. Vet Radiol Ultrasound. (2019) 60:E1-5. doi: 10.1111/vru.12506

81. Koestner A, Bilzer T, Fatzer R, Schulman FY, Summers BA, Van Winkle TJ. Histological Classification of Tumors of the Nervous System of Domestic Animals. Washington, DC: Armed Forces Institute of Pathology (1999).

82. Rissi DR, Barber R, Burnum A, Miller AD. Canine spinal cord glioma. J Vet Diagn Invest. (2017) 29:126-32. doi: 10.1177/10406387166 73127

83. Stoica G, Kim HT, Hall DG, Coates JR. Morphology, immunohistochemistry, and genetic alterations in dog astrocytomas. Vet Pathol. (2004) 41:10-9. doi: 10.1354/vp.41-1-10

84. Lipsitz D, Higgins RJ, Kortz GD, Dickinson PJ, Bollen AW, Naydan $\mathrm{DK}$, et al. Glioblastoma multiforme: clinical findings, magnetic resonance imaging, and pathology in five dogs. Vet Pathol. (2003) 40:659-69. doi: $10.1354 /$ vp.40-6-659

85. Kishimoto TE, Uchida K, Thongtharb A, Shibato T, Chambers JK, Nibe K, et al. Expression of oligodendrocyte precursor cell markers in canine oligodendrogliomas. Vet Pathol. (2018) 55:634-44. doi: 10.1177/0300985818777794

86. Higgins RJ, Dickinson PJ, Lecouteur RA, Bollen AW, Wang H, Wang H, et al. Spontaneous canine gliomas: overexpression of EGFR, PDGFRalpha and IGFBP2 demonstrated by tissue microarray immunophenotyping. J Neurooncol. (2010) 98:49-55. doi: 10.1007/s11060-0090072-5

87. Fraser AR, Bacci B, Le Chevoir MA, Long SN. Epidermal growth factor receptor and Ki-67 expression in canine gliomas. Vet Pathol. (2016) 53:11317. doi: 10.1177/0300985816644301

88. Jankovsky JM, Newkirk KM, Ilha MR, Newman SJ. COX-2 and ckit expression in canine gliomas. Vet Comp Oncol. (2013) 11:63-9. doi: 10.1111/j.1476-5829.2011.00302.x 
89. Fraser AR, Bacci B, Le Chevoir MA, Long SN. Isocitrate dehydrogenase 1 expression in canine gliomas. J Comp Pathol. (2018) 165:33-9. doi: 10.1016/j.jcpa.2018.09.005

90. Sloma EA, Creneti CT, Erb HN, Miller AD. Characterization of inflammatory changes associated with canine oligodendroglioma. J Comp Pathol. (2015) 153:92-100. doi: 10.1016/j.jcpa.2015.05.003

91. Filley A, Henriquez M, Bhowmik T, Tewari BN, Rao X, Wan J, et al. Immunologic and gene expression profiles of spontaneous canine oligodendrogliomas. J Neurooncol. (2018) 137:469-79. doi: 10.1007/s11060-018-2753-4

92. Herranz C, Fernandez F, Martin-Ibanez R, Blasco E, Crespo E, De La Fuente $\mathrm{C}$, et al. Spontaneously arising canine glioma as a potential model for human glioma. J Comp Pathol. (2016) 154:169-79. doi: 10.1016/j.jcpa.2015.12.001

93. Boudreau CE, York D, Higgins RJ, Lecouteur RA, Dickinson PJ. Molecular signalling pathways in canine gliomas. Vet Comp Oncol. (2017) 15:133-50. doi: $10.1111 /$ vco. 12147

94. Amin S, Boudreau B, Martinez-Ledesma JE, Anderson K, Kim H, Johnson K, et al. Comparative molecular life history of spontaneous canine and human glioma. Neuro Oncol. (2018) 20:vi64-65. doi: 10.1093/neuonc/noy148.262

95. Amin S, Martinez-Ledesma JE, Boudreau B, Kim H, Johnson KC, Dickinson $\mathrm{PV}$, et al. Genomic profiling of canine glioma: comparative analyses with respect to drivers of human glioma. Cancer Res. (2018) 78:1176. doi: 10.1158/1538-7445.AM2018-1176

96. Dickinson PJ, York D, Higgins RJ, Lecouteur RA, Joshi N, Bannasch D. Chromosomal aberrations in canine gliomas define candidate genes and common pathways in dogs and humans. J Neuropathol Exp Neurol. (2016) 75:700-10. doi: 10.1093/jnen/nlw042

97. Connolly NP, Shetty AC, Stokum JA, Hoeschele I, Siegel MB, Miller CR, et al. Cross-species transcriptional analysis reveals conserved and hostspecific neoplastic processes in mammalian glioma. Sci Rep. (2018) 8:1180. doi: 10.1038/s41598-018-19451-6

98. Miller CR, Perry A. Glioblastoma. Arch Pathol Lab Med. (2007) 131:397-406. doi: 10.1043/1543-2165(2007)131[397:G]2.0.CO;2

99. Coons SW, Johnson PC, Scheithauer BW, Yates AJ, Pearl DK. Improving diagnostic accuracy and interobserver concordance in the classification and grading of primary gliomas. Cancer. (1997) 79:1381-93.

100. Van Den Bent MJ. Interobserver variation of the histopathological diagnosis in clinical trials on glioma: a clinician's perspective. Acta Neuropathol. (2010) 120:297-304. doi: 10.1007/s00401-010-0725-7

101. Burger PC. What is an oligodendroglioma? Brain Pathol. (2002) 12:257-9. doi: 10.1111/j.1750-3639.2002.tb00440.x

102. Sahm F, Reuss D, Koelsche C, Capper D, Schittenhelm J, Heim S, et al. Farewell to oligoastrocytoma: in situ molecular genetics favor classification as either oligodendroglioma or astrocytoma. Acta Neuropathol. (2014) 128:551-9. doi: 10.1007/s00401-014-1326-7

103. Phillips HS, Kharbanda S, Chen R, Forrest WF, Soriano RH, Wu TD, et al. Molecular subclasses of high-grade glioma predict prognosis, delineate a pattern of disease progression, and resemble stages in neurogenesis. Cancer Cell. (2006) 9:157-73. doi: 10.1016/j.ccr.2006.02.019

104. Vitucci M, Hayes DN, Miller CR. Gene expression profiling of gliomas: merging genomic and histopathological classification for personalised therapy. Br J Cancer. (2011) 104:545-53. doi: 10.1038/sj.bjc.6606031

105. Parsons DW, Jones S, Zhang X, Lin JC, Leary RJ, Angenendt P, et al. An integrated genomic analysis of human glioblastoma multiforme. Science. (2008) 321:1807-12. doi: 10.1126/science.1164382

106. Yan H, Parsons DW, Jin G, Mclendon R, Rasheed BA, Yuan W, et al. IDH1 and IDH2 mutations in gliomas. N Engl J Med. (2009) 360:765-73. doi: 10.1056/NEJMoa0808710

107. Smith JS, Alderete B, Minn Y, Borell TJ, Perry A, Mohapatra G, et al. Localization of common deletion regions on $1 \mathrm{p}$ and $19 \mathrm{q}$ in human gliomas and their association with histological subtype. Oncogene. (1999) 18:4144-52. 10.1038/sj.onc.1202759 doi: 10.1038/sj.onc.1202759

108. Jenkins RB, Blair H, Ballman KV, Giannini C, Arusell RM, Law M, et al. A $\mathrm{t}(1 ; 19)(\mathrm{q} 10 ; \mathrm{p} 10)$ mediates the combined deletions of $1 \mathrm{p}$ and $19 \mathrm{q}$ and predicts a better prognosis of patients with oligodendroglioma. Cancer Res. (2006) 66:9852-61. doi: 10.1158/0008-5472.CAN-06-1796

109. Eckel-Passow JE, Lachance DH, Molinaro AM, Walsh KM, Decker PA, Sicotte $\mathrm{H}$, et al. Glioma groups based on $1 \mathrm{p} / 19 \mathrm{q}$, IDH, and TERT promoter mutations in tumors. N Engl J Med. (2015) 372:2499-508. doi: 10.1056/NEJMoa1407279

110. Cancer Genome Atlas Research N, Brat DJ, Verhaak RG, Aldape KD, Yung WK, Salama SR, et al. Comprehensive, integrative genomic analysis of diffuse lower-grade gliomas. N Engl J Med. (2015) 372:2481-98. doi: 10.1056/NEJMoa1402121

111. Bettegowda C, Agrawal N, Jiao Y, Sausen M, Wood LD, Hruban RH, et al. Mutations in CIC and FUBP1 contribute to human oligodendroglioma. Science. (2011) 333:1453-5. doi: 10.1126/science.1210557

112. Wiestler B, Capper D, Sill M, Jones DT, Hovestadt V, Sturm D, et al. Integrated DNA methylation and copy-number profiling identify three clinically and biologically relevant groups of anaplastic glioma. Acta Neuropathol. (2014) 128:561-71. doi: 10.1007/s00401-014-1315-x

113. Suzuki H, Aoki K, Chiba K, Sato Y, Shiozawa Y, Shiraishi Y, et al. Mutational landscape and clonal architecture in grade II and III gliomas. Nat Genet. (2015) 47:458-68. doi: 10.1038/ng.3273

114. Aibaidula A, Chan AK, Shi Z, Li Y, Zhang R, Yang R, et al. Adult IDH wildtype lower-grade gliomas should be further stratified. Neuro Oncol. (2017) 19:1327-37. doi: 10.1093/neuonc/nox078

115. Ceccarelli M, Barthel FP, Malta TM, Sabedot TS, Salama SR, Murray $\mathrm{BA}$, et al. Molecular profiling reveals biologically discrete subsets and pathways of progression in diffuse glioma. Cell. (2016) 164:550-63. doi: 10.1016/j.cell.2015.12.028

116. Louis DN, Perry A, Reifenberger G, Von Deimling A, Figarella-Branger D, Cavenee WK, et al. The 2016 world health organization classification of tumors of the central nervous system: a summary. Acta Neuropathol. (2016) 131:803-20. doi: 10.1007/s00401-016-1545-1

117. Rissi DR. A retrospective study of skull base neoplasia in 42 dogs. J Vet Diagn Invest. (2015) 27:743-8. doi: 10.1177/1040638715611706

118. Schulman FY, Ribas JL, Carpenter JL, Sisson AF, Lecouteur RA. Intracranial meningioma with pulmonary metastasis in three dogs. Vet Pathol. (1992) 29:196-202. doi: 10.1177/030098589202900302

119. Montoliu P, Anor S, Vidal E, Pumarola M. Histological and immunohistochemical study of 30 cases of canine meningioma. J Comp Pathol. (2006) 135:200-7. doi: 10.1016/j.jcpa.2006.06.006

120. Salvadori C, Pintore MD, Ricci E, Konar M, Tartarelli CL, Gasparinetti N, et al. Microcystic meningioma of the fourth ventricle in a dog. J Vet Med Sci. (2011) 73:367-70. doi: 10.1292/jvms.10-0337

121. Takeuchi Y, Ohnishi Y, Matsunaga S, Nakayama H, Uetsuka K. Intracranial meningioma with polygonal granular cell appearance in a Chihuahua. J Vet Med Sci. (2008) 70:529-32. 10.1292/jvms.70.529

122. Mandara MT, Reginato A, Foiani G, Baroni M, Poli F, Gasparinetti N, et al. Papillary meningioma in the dog: a clinicopathological case series study. Res Vet Sci. (2015) 100:213-9. doi: 10.1016/j.rvsc.2015.03.029

123. Schoniger S, Woolford L, Jutras L, Head E, De Lahunta A, Summers BA. Unusual features in four canine meningiomas. J Comp Pathol. (2013) 149:237-41. doi: 10.1016/j.jcpa.2013.03.003

124. Boozer LB, Davis TW, Borst LB, Zseltvay KM, Olby NJ, Mariani CL. Characterization of immune cell infiltration into canine intracranial meningiomas. Vet Pathol. (2012) 49:784-95. doi: 10.1177/0300985811417249

125. Al-Nadaf S, Platt SR, Kent M, Northrup N, Howerth EW. Minimal interleukin expression in canine intracranial meningiomas. Vet Rec. (2015) 177:75. doi: 10.1136/vr.103135

126. Grenier JK, Foureman PA, Sloma EA, Miller AD. RNA-seq transcriptome analysis of formalin fixed, paraffin-embedded canine meningioma. PLoS ONE. (2017) 12:e0187150. doi: 10.1371/journal.pone.0187150

127. Ramos-Vara JA, Miller MA, Gilbreath E, Patterson JS. Immunohistochemical detection of CD34, E-cadherin, claudin-1, glucose transporter 1, laminin, and protein gene product 9.5 in 28 canine and 8 feline meningiomas. Vet Pathol. (2010) 47:725-37. doi: 10.1177/0300985810364528

128. Johnson GC, Coates JR, Wininger F. Diagnostic immunohistochemistry of canine and feline intracalvarial tumors in the age of brain biopsies. Vet Pathol. (2014) 51:146-60. doi: 10.1177/0300985813509387

129. Ide T, Uchida K, Suzuki K, Kagawa Y, Nakayama H. Expression of cell adhesion molecules and doublecortin in canine anaplastic meningiomas. Vet Pathol. (2011) 48:292-301. doi: 10.1177/0300985810389312

130. Theon AP, Lecouteur RA, Carr EA, Griffey SM. Influence of tumor cell proliferation and sex-hormone receptors on effectiveness of radiation 
therapy for dogs with incompletely resected meningiomas. J Am Vet Med Assoc. (2000) 216:701-707:684-705. doi: 10.2460/javma.2000.216.701

131. Mandara MT, Ricci G, Rinaldi L, Sarli G, Vitellozzi G. Immunohistochemical identification and image analysis quantification of oestrogen and progesterone receptors in canine and feline meningioma. J Comp Pathol. (2002) 127:214-8. doi: 10.1053/jcpa.2002.0572

132. Platt SR, Scase TJ, Adams V, Wieczorek L, Miller J, Adamo F, et al. Vascular endothelial growth factor expression in canine intracranial meningiomas and association with patient survival. J Vet Intern Med. (2006) 20:663-8. doi: 10.1111/j.1939-1676.2006.tb02912.x

133. Dickinson PJ, Sturges BK, Higgins RJ, Roberts BN, Leutenegger CM, Bollen AW, et al. Vascular endothelial growth factor mRNA expression and peritumoral edema in canine primary central nervous system tumors. Vet Pathol. (2008) 45:131-9. doi: 10.1354/vp.45-2-131

134. Matiasek LA, Platt SR, Adams V, Scase TJ, Keys D, Miller J, et al. Ki-67 and vascular endothelial growth factor expression in intracranial meningiomas in dogs. J Vet Intern Med. (2009) 23:146-51. doi: $10.1111 /$ j.1939-1676.2008.0235.x

135. Mandara MT, Pavone S, Mandrioli L, Bettini G, Falzone C, Baroni M. Matrix metalloproteinase-2 and matrix metalloproteinase-9 expression in canine and feline meningioma. Vet Pathol. (2009) 46:836-45. doi: 10.1354/vp.08-VP-0185-M-FL

136. Beltran E, Matiasek K, De Risio L, De Stefani A, Feliu-Pascual AL, Matiasek LA. Expression of MMP-2 and MMP-9 in benign canine rostrotentorial meningiomas is not correlated to the extent of peritumoral edema. Vet Pathol. (2013) 50:1091-8. doi: 10.1177/0300985813481610

137. Mandara MT, Reginato A, Foiani G, De Luca S, Guelfi G. Gene expression of matrix metalloproteinases and their inhibitors (TIMPs) in meningiomas of dogs. J Vet Intern Med. (2017) 31:1816-21. doi: 10.1111/jvim.14809

138. Mandrioli L, Panarese S, Cesari A, Mandara MT, Marcato PS, Bettini G. Immunohistochemical expression of h-telomerase reverse transcriptase in canine and feline meningiomas. J Vet Sci. (2007) 8:111-5. doi: 10.4142/jvs.2007.8.2.111

139. Foiani G, Guelfi G, Chiaradia E, Mancini F, Trivelli C, Vitellozzi G, et al. Somatostatin receptor 2 expression in canine meningioma. J Comp Pathol. (2019) 166:59-68. doi: 10.1016/j.jcpa.2018.11.002

140. Pierce JT, Cho SS, Nag S, Zeh R, Jeon J, Holt D, et al. Folate receptor overexpression in human and canine meningiomas-immunohistochemistry and case report of intraoperative molecular imaging. Neurosurgery. (2018) 85:359-68. doi: 10.1093/neuros/nyy356

141. Dickinson PJ, Surace EI, Cambell M, Higgins RJ, Leutenegger CM, Bollen AW, et al. Expression of the tumor suppressor genes NF2:4.1B, and TSLC1 in canine meningiomas. Vet Pathol. (2009) 46:884-92. doi: 10.1354/vp.08-VP-0251-D-FL

142. Coy S, Rashid R, Stemmer-Rachamimov A, Santagata S. An update on the CNS manifestations of neurofibromatosis type 2. Acta Neuropathol. (2019) 1-23. doi: 10.1007/s00401-019-02029-5. [Epub ahead of print].

143. Hao S, Huang G, Feng J, Li D, Wang K, Wang L, et al. Non-NF2 mutations have a key effect on inhibitory immune checkpoints and tumor pathogenesis in skull base meningiomas. J Neurooncol. (2019) 144:11-20. doi: 10.1007/s11060-019-03198-9

144. Muscatello LV, Avallone G, Serra F, Seuberlich T, Mandara MT, Siso $\mathrm{S}$, et al. Glomeruloid microvascular proliferation, desmoplasia, and high proliferative index as potential indicators of high grade canine choroid plexus tumors. Vet Pathol. (2018) 55:391-401. doi: 10.1177/03009858177 54124

145. Pastorello A, Constantino-Casas F, Archer J. Choroid plexus carcinoma cells in the cerebrospinal fluid of a staffordshire bull terrier. Vet Clin Pathol. (2010) 39:505-10. doi: 10.1111/j.1939-165X.2010.00270.x

146. Miller AD, Koehler JW, Donovan TA, Stewart JE, Porter BF, Rissi DR, et al. Canine ependymoma: diagnostic criteria and common pitfalls. Vet Pathol. (2019) 56:860-7. doi: 10.1177/0300985819859872

147. Choi EJ, Sloma EA, Miller AD. Kir7.1 immunoreactivity in canine choroid plexus tumors. J Vet Diagn Invest. (2016) 28:464-8. doi: $10.1177 / 1040638716650239$

148. Ide T, Uchida K, Kikuta F, Suzuki K, Nakayama H. Immunohistochemical characterization of canine neuroepithelial tumors. Vet Pathol. (2010) 47:74150. doi: $10.1177 / 0300985810363486$
149. Nentwig A, Higgins RJ, Francey T, Doherr M, Zurbriggen A, Oevermann A. Aberrant E-cadherin, beta-catenin, and glial fibrillary acidic protein (GFAP) expression in canine choroid plexus tumors. J Vet Diagn Invest. (2012) 24:14-22. doi: 10.1177/1040638711425940

150. Reginato A, Girolami D, Menchetti L, Foiani G, Mandara MT. Ecadherin, N-cadherin expression and histologic characterization of canine choroid plexus tumors. Vet Pathol. (2016) 53:788-91. doi: $10.1177 / 0300985815620844$

151. Ancona D, York D, Higgins RJ, Bannasch D, Dickinson PJ. Comparative cytogenetic analysis of dog and human choroid plexus tumors defines syntenic regions of genomic loss. J Neuropathol Exp Neurol. (2018) 77:413-9. doi: 10.1093/jnen/nly020

152. Dickinson PJ. Advances in diagnostic and treatment modalities for intracranial tumors. J Vet Intern Med. (2014) 28:1165-85. doi: 10.1111 /jvim. 12370

153. Rossmeisl J. New treatment modalities for brain tumors in dogs and cats. Vet Clin North Am Small Anim Pract. (2014) 44:1013-38. doi: 10.1016/j.cvsm.2014.07.003

154. Hu H, Barker A, Harcourt-Brown T, Jeffery N. Systematic review of brain tumor treatment in dogs. J Vet Intern Med. (2015) 29:1456-63. doi: 10.1111/jvim.13617

155. De Stefani A, De Risio L, Platt SR, Matiasek L, Lujan-Feliu-Pascual A, Garosi LS. Surgical technique, postoperative complications and outcome in 14 dogs treated for hydrocephalus by ventriculoperitoneal shunting. Vet Surg. (2011) 40:183-91. doi: 10.1111/j.1532-950X.2010.00764.x

156. Moore SA. Managing neuropathic pain in dogs. Front Vet Sci. (2016) 3:12. doi: $10.3389 /$ fvets. 2016.00012

157. Heidner GL, Kornegay JN, Page RL, Dodge RK, Thrall DE. Analysis of survival in a retrospective study of 86 dogs with brain tumors. J Vet Intern Med. (1991) 5:219-26. doi: 10.1111/j.1939-1676.1991.tb00952.x

158. Van Meervenne S, Verhoeven PS, De Vos J, Gielen IM, Polis I, Van Ham LM. Comparison between symptomatic treatment and lomustine supplementation in 71 dogs with intracranial, space-occupying lesions. Vet Comp Oncol. (2014) 12:67-77. doi: 10.1111/j.1476-5829.2012.00336.x

159. Moirano SJ, Dewey CW, Wright KZ, Cohen PW. Survival times in dogs with presumptive intracranial gliomas treated with oral lomustine: a comparative retrospective study (2008-2017). Vet Comp Oncol. (2018) 16:459-66. doi: 10.1111/vco.12401

160. Dolera M, Malfassi L, Bianchi C, Carrara N, Finesso S, Marcarini $\mathrm{S}$, et al. Frameless stereotactic radiotherapy alone and combined with temozolomide for presumed canine gliomas. Vet Comp Oncol. (2018) 16:90101. doi: $10.1111 /$ vco. 12316

161. Mohammed SI, Craig BA, Mutsaers AJ, Glickman NW, Snyder PW, Degortari AE, et al. Effects of the cyclooxygenase inhibitor, piroxicam, in combination with chemotherapy on tumor response, apoptosis, and angiogenesis in a canine model of human invasive urinary bladder cancer. Mol Cancer Ther. (2003) 2:183-8.

162. Roth P, Regli L, Tonder M, Weller M. Tumor-associated edema in brain cancer patients: pathogenesis and management. Expert Rev Anticancer Ther. (2013) 13:1319-25. doi: 10.1586/14737140.2013.852473

163. Rossmeisl JH Jr, Robertson JL, Zimmerman KL, Higgins MA, Geiger DA. Cyclooxygenase-2 (COX-2) expression in canine intracranial meningiomas. Vet Comp Oncol. (2009) 7:173-80. doi: 10.1111/j.1476-5829.2009.00188.x

164. Dickinson PJ, Roberts BN, Higgins RJ, Leutenegger CM, Bollen AW, Kass PH, et al. Expression of receptor tyrosine kinases VEGFR-1 (FLT-1), VEGFR2 (KDR), EGFR-1, PDGFRalpha and c-Met in canine primary brain tumours. Vet Comp Oncol. (2006) 4:132-40. doi: 10.1111/j.1476-5829.2006.00101.x

165. Neal RE II, Rossmeisl JH Jr, D’alfonso V, Robertson JL, Garcia $\mathrm{PA}$, Elankumaran S, Davalos RV. In vitro and numerical support for combinatorial irreversible electroporation and electrochemotherapy glioma treatment. Ann Biomed Eng. (2014) 42:475-87. doi: 10.1007/s10439-013-0923-2

166. Bentley RT, Thomovsky SA, Miller MA, Knapp DW, Cohen-Gadol AA. Canine (Pet Dog) tumor microsurgery and intratumoral concentration and safety of metronomic chlorambucil for spontaneous glioma: a phase i clinical trial. World Neurosurg. (2018) 116:e534-42. doi: 10.1016/j.wneu.2018.05.027

167. Rossmeisl JH Jr, Garcia PA, Daniel GB, Bourland JD, Debinski W, Dervisis $\mathrm{N}$, et al. Invited review-neuroimaging response assessment criteria for brain 
tumors in veterinary patients. Vet Radiol Ultrasound. (2014) 55:115-32. doi: $10.1111 /$ vru. 12118

168. Nanda A, Bir SC, Maiti TK, Konar SK, Missios S, Guthikonda B. Relevance of Simpson grading system and recurrence-free survival after surgery for World Health Organization Grade I meningioma. J Neurosurg. (2017) 126:201-11. doi: 10.3171/2016.1.JNS151842

169. Chow KE, Tyrrell D, Long SN. Early postoperative magnetic resonance imaging findings in five dogs with confirmed and suspected brain tumors. Vet Radiol Ultrasound. (2015) 56:531-9. doi: 10.1111/vru.12248

170. Kostolich M, Dulisch ML. A surgical approach to the canine olfactory bulb for meningioma removal. Vet Surg. (1987) 16:273-7. doi: 10.1111/j.1532-950X.1987.tb00952.x

171. Axlund TW, Mcglasson ML, Smith AN. Surgery alone or in combination with radiation therapy for treatment of intracranial meningiomas in dogs: 31 cases (1989-2002). J Am Vet Med Assoc. (2002) 221:1597-600. doi: 10.2460/javma.2002.221.1597

172. Rossmeisl J. Craniectomy for the treatment of canine meningiomas. In: Proceedings of the American College of Veterinary Surgery Symposium. Washington, DC. (2003).

173. Klopp LS, Rao S. Endoscopic-assisted intracranial tumor removal in dogs and cats: long-term outcome of 39 cases. J Vet Intern Med. (2009) 23:108-15. doi: 10.1111/j.1939-1676.2008.0234.x

174. Sunol A, Mascort J, Font C, Bastante AR, Pumarola M, Feliu-Pascual AL. Long-term follow-up of surgical resection alone for primary intracranial rostrotentorial tumors in dogs: 29 cases (2002-2013). Open Vet J. (2017) 7:375-83. doi: 10.4314/ovj.v7i4.14

175. Andersen BM, Pluhar GE, Seiler CE, Goulart MR, Santacruz KS, Schutten MM, et al. Vaccination for invasive canine meningioma induces in situ production of antibodies capable of antibodydependent cell-mediated cytotoxicity. Cancer Res. (2013) 73:2987-97. doi: 10.1158/0008-5472.CAN-12-3366

176. Greco JJ, Aiken SA, Berg JM, Monette S, Bergman PJ. Evaluation of intracranial meningioma resection with a surgical aspirator in dogs: 17 cases (1996-2004). J Am Vet Med Assoc. (2006) 229:394-400. doi: 10.2460/javma.229.3.394

177. Keyerleber MA, Mcentee MC, Farrelly J, Thompson MS, Scrivani PV, Dewey CW. Three-dimensional conformal radiation therapy alone or in combination with surgery for treatment of canine intracranial meningiomas. Vet Comp Oncol. (2015) 13:385-97. doi: 10.1111/vco.12054

178. Thankey K, Faissler D, Kavirayani A, Keating JH, Mcdonnell JJ. Clinical presentation and outcome in dogs with histologically confirmed choroid plexus papillomas. J Vet Intern Med. (2006) 20:782-3.

179. Marino DJ, Dewey CW, Loughin CA, Marino LJ. Severe hyperthermia, hypernatremia, and early postoperative death after transethmoidal cavitron ultrasonic surgical aspirator (CUSA)-assisted diencephalic mass removal in 4 dogs and 2 cats. Vet Surg. (2014) 43:888-94. doi: 10.1111/j.1532-950X.2014.12238.x

180. Maclellan JD, Arnold SA, Dave AC, Hunt MA, Pluhar GE. Association of magnetic resonance imaging-based preoperative tumor volume with postsurgical survival time in dogs with primary intracranial glioma. J Am Vet Med Assoc. (2018) 252:98-102. doi: 10.2460/javma. 252.1.98

181. Packer R, Engel S. Onscreen-guided brain tumor resection through registration of a variable-suction tissue resection device with a neuronavigation system. J Vet Intern Med. (2015) 29:1264.

182. Nakano Y, Nakata K, Shibata S, Heishima Y, Nishida H, Sakai H, et al. Fluorescein sodium-guided resection of intracranial lesions in $22 \mathrm{dogs}$. Vet Surg. (2018) 47:302-9. doi: 10.1111/vsu.12763

183. Forward AK, Volk HA, De Decker S. Postoperative survival and early complications after intracranial surgery in dogs. Vet Surg. (2018) 47:549-54. doi: 10.1111/vsu. 12785

184. Lester NV, Hopkins AL, Bova FJ, Friedman WA, Buatti JM, Meeks SL, et al. Radiosurgery using a stereotactic headframe system for irradiation of brain tumors in dogs. J Am Vet Med Assoc. (2001) 219:1562-7:1550. doi: 10.2460/javma.2001.219.1562

185. Turrel JM, Fike JR, Lecouteur RA, Pflugfelder CM, Borcich JK. Radiotherapy of brain tumors in dogs. J Am Vet Med Assoc. (1984) 184:82-6.
186. Evans SM, Dayrell-Hart B, Powlis W, Christy G, Vanwinkle T. Radiation therapy of canine brain masses. J Vet Intern Med. (1993) 7:216-9. doi: 10.1111/j.1939-1676.1993.tb01010.x

187. Brearley MJ, Jeffery ND, Phillips SM, Dennis R. Hypofractionated radiation therapy of brain masses in dogs: a retrospective analysis of survival of 83 cases (1991-1996). J Vet Intern Med. (1999) 13:408-12. doi: 10.1111/j.1939-1676.1999.tb01454.x

188. Spugnini EP, Thrall DE, Price GS, Sharp NJ, Munana K, Page RL. Primary irradiation of canine intracranial masses. Vet Radiol Ultrasound. (2000) 41:377-80. doi: 10.1111/j.1740-8261.2000.tb02091.x

189. Bley CR, Sumova A, Roos M, Kaser-Hotz B. Irradiation of brain tumors in dogs with neurologic disease. J Vet Intern Med. (2005) 19:849-54. doi: 10.1111/j.1939-1676.2005.tb02776.x

190. Mariani CL, Schubert TA, House RA, Wong MA, Hopkins AL, Barnes Heller HL, et al. Frameless stereotactic radiosurgery for the treatment of primary intracranial tumours in dogs. Vet Comp Oncol. (2015) 13:409-23. doi: $10.1111 /$ vco. 12056

191. Schwarz P, Meier V, Soukup A, Drees R, Besserer J, Beckmann K, et al. Comparative evaluation of a novel, moderately hypofractionated radiation protocol in 56 dogs with symptomatic intracranial neoplasia. J Vet Intern Med. (2018) 32:2013-20. doi: 10.1111/jvim.15324

192. Khanna C, London C, Vail D, Mazcko C, Hirschfeld S. Guiding the optimal translation of new cancer treatments from canine to human cancer patients. Clin Cancer Res. (2009) 15:5671-7. doi: 10.1158/1078-0432.CCR-09-0719

193. Leblanc AK, Mazcko C, Brown DE, Koehler JW, Miller AD, Miller CR, et al. Creation of an NCI comparative brain tumor consortium: informing the translation of new knowledge from canine to human brain tumor patients. Neuro Oncol. (2016) 18:1209-18. doi: 10.1093/neuonc/now051

194. Schwartz JA, Shetty AM, Price RE, Stafford RJ, Wang JC, Uthamanthil RK, et al. Feasibility study of particle-assisted laser ablation of brain tumors in orthotopic canine model. Cancer Res. (2009) 69:1659-67. doi: 10.1158/0008-5472.CAN-08-2535

195. Rossmeisl JH Jr, Garcia PA, Pancotto TE, Robertson JL, HenaoGuerrero N, Neal RE II, Ellis TL, et al. Safety and feasibility of the NanoKnife system for irreversible electroporation ablative treatment of canine spontaneous intracranial gliomas. J Neurosurg. (2015) 123:1008-25. doi: $10.3171 / 2014.12 . J N S 141768$

196. Latouche EL, Arena CB, Ivey JW, Garcia PA, Pancotto TE, Pavlisko N, et al. High-frequency irreversible electroporation for intracranial meningioma: a feasibility study in a spontaneous canine tumor model. Technol Cancer Res Treat. (2018) 17:1533033818785285. doi: 10.1177/1533033818785285

197. Rossmeisl JH, Herpai D, Robertson JL, Dickinson PJ, Tatter SB, Debinksi W. Tolerability and intial efficacy of convection-enhanced delivery of combinatorial IL-12RA2 and EphA2 targeted cytotoxins to dogs with spontaneous intracranial malignant gliomas. Neuro Oncol. (2017) 19:iii56. doi: 10.1093/neuonc/nox036.202

198. 198. Dickinson PJ, Lecouteur RA, Higgins RJ, Bringas JR, Larson RF, Yamashita Y, et al. Canine spontaneous glioma: a translational model system for convection-enhanced delivery. Neuro Oncol. (2010) 12:928-40. doi: 10.1093/neuonc/noq046

199. Robbins JM, Dickinson PJ, York D, Sturges BK, Martin B, Higgins RJ, et al. Evaluation of delivery of retroviral replicating vector, TOCA 511, in spontaneous canine brain tumor. Neuro Oncol. (2012) 14:vi48.

200. Rossmeisl JH, Hall-Manning K, Robertson JL, King JN, Davalos RV, Debinski $\mathrm{W}$, et al. Expression and activity of the urokinase plasminogen activator system in canine primary brain tumors. Onco Targets Ther. (2017) 10:207785. doi: $10.2147 /$ OTT.S132964

201. Freeman AC, Platt SR, Holmes S, Kent M, Robinson K, Howerth E, et al. Convection-enhanced delivery of cetuximab conjugated ironoxide nanoparticles for treatment of spontaneous canine intracranial gliomas. J Neurooncol. (2018) 137:653-63. doi: 10.1007/s11060-0182764-1

202. Young JS, Bernal G, Polster SP, Nunez L, Larsen GF, Mansour $\mathrm{N}$, et al. Convection-enhanced delivery of polymeric nanoparticles encapsulating chemotherapy in canines with spontaneous supratentorial tumors. World Neurosurg. (2018) 117:e698-704. doi: 10.1016/j.wneu.2018. 06.114 
203. Kent M, Leung P, Dickinson P, Sturges B, Ng S, Bedard C, et al. Use of the novel oxygen carrier protein, ZOX, in dogs with intracranial masses. $J$ Vet Intern Med. (2016) 30:1530.

204. Macdiarmid JA, Langova V, Bailey D, Pattison ST, Pattison SL, Christensen $\mathrm{N}$, et al. Targeted doxorubicin delivery to brain tumors via minicells: proof of principle using dogs with spontaneously occurring tumors as a model. PLOS ONE. (2016) 11:e0151832. doi: 10.1371/journal.pone. 0151832

205. Joshi AD, Botham RC, Schlein LJ, Roth HS, Mangraviti A, Borodovsky A, et al. Synergistic and targeted therapy with a procaspase-3 activator and temozolomide extends survival in glioma rodent models and is feasible for the treatment of canine malignant glioma patients. Oncotarget. (2017) 8:80124-38. doi: 10.18632/oncotarget. 19085

206. Yaghi NK, Wei J, Hashimoto Y, Kong LY, Gabrusiewicz K, Nduom EK, et al. Immune modulatory nanoparticle therapeutics for intracerebral glioma. Neuro Oncol. (2017) 19:372-82. doi: 10.1093/neuonc/ now198

207. Pluhar GE, Grogan PT, Seiler C, Goulart M, Santacruz KS, Carlson C, et al. Anti-tumor immune response correlates with neurological symptoms in a dog with spontaneous astrocytoma treated by gene and vaccine therapy. Vaccine. (2010) 28:3371-8. doi: 10.1016/j.vaccine.2010. 02.082

208. Xiong W, Candolfi M, Liu C, Muhammad AK, Yagiz K, Puntel M, et al. Human Flt3L generates dendritic cells from canine peripheral blood precursors: implications for a dog glioma clinical trial. PLoS ONE. (2010) 5:e11074. doi: 10.1371/journal.pone.0011074
209. Olin MR, Ampudia-Mesias E, Pennell CA, Sarver A, Chen CC, Moertel CL, et al. Treatment combining CD200 immune checkpoint inhibitor and tumor-lysate vaccination after surgery for pet dogs with high-grade glioma. Cancers. (2019) 11:137. doi: 10.3390/cancers11020137

210. Lai SR, Castello SA, Robinson AC, Koehler JW. In vitro anti-tubulin effects of mebendazole and fenbendazole on canine glioma cells. Vet Comp Oncol. (2017) 15:1445-54. doi: 10.1111/vco.12288

211. Rossmeisl J. Maximizing local access to therapeutic deliveries in glioblastoma. Part V: Clinically relevant model for testing new therapeutic approaches. In: DeVlesschouwer $S$, editor. Glioblastoma. Brisbane, AU: Codon Publications. (2017) 21:405-25. doi: 10.15586/codon.glioblastoma.2017.ch21

Conflict of Interest: The authors declare that the research was conducted in the absence of any commercial or financial relationships that could be construed as a potential conflict of interest.

The reviewer MRC declared a shared affiliation, with no collaboration, with one of the authors, CRM, to the handling editor at time of review.

Copyright () 2019 Miller, Miller and Rossmeisl. This is an open-access article distributed under the terms of the Creative Commons Attribution License (CC BY). The use, distribution or reproduction in other forums is permitted, provided the original author(s) and the copyright owner(s) are credited and that the original publication in this journal is cited, in accordance with accepted academic practice. No use, distribution or reproduction is permitted which does not comply with these terms. 